Article

\title{
Effect of Radiation Crosslinking and Surface Modification of Cellulose Fibers on Properties and Characterization of Biopolymer Composites
}

\author{
Petr Lenfeld *(D), Pavel Brdlík, Martin Borůvka (1), Luboš Běhálek (1) and Jiří Habr \\ Faculty of Mechanical Engineering, Technical University of Liberec, Studentska 2, 46117 Liberec, Czech Republic; \\ pavel.brdlik@tul.cz (P.B.); martin.boruvka@tul.cz (M.B.); lubos.behalek@tul.cz (L.B.); jiri.habr@tul.cz (J.H.) \\ * Correspondence: petr.lenfeld@tul.cz; Tel.: +420-48-535-3455
}

Received: 26 November 2020; Accepted: 12 December 2020; Published: 16 December 2020

\begin{abstract}
Recently, polymers have become the fastest growing and most widely used material in a huge number of applications in almost all areas of industry. In addition to standard polymer composites with synthetic matrices, biopolymer composites based on PLA and PHB matrices filled with fibers of plant origin are now increasingly being used in selected advanced industrial applications. The article deals with the evaluation of the influence and effect of the type of surface modification of cellulose fibers using physical methods (low-temperature plasma and ozone application) and chemical methods (acetylation) on the final properties of biopolymer composites. In addition to the surface modification of natural fibers, an additional modification of biocomposite structural systems by radiation crosslinking using gamma radiation was also used. The components of the biopolymer composite were a matrix of PLA and PHBV and the filler was natural cellulose fibers in a constant percentage volume of $20 \%$. Test specimens were made from compounds of prepared biopolymer structures, on which selected tests had been performed to evaluate the properties and mechanical characterization of biopolymer composites. Electron microscopy was used to evaluate the failure and characterization of fracture surfaces of biocomposites.
\end{abstract}

Keywords: biopolymer composite; polymer; biopolymer; natural fibers; surface modification; radiation crosslinking; mechanical behavior; fracture surface

\section{Introduction}

Polymers and their composites are currently among the most progressively developing materials and there can be no doubt that they are key to modern technical society. In recent years, research into these materials has not only focused on highly durable synthetic composites, but also on renewable and sustainable natural materials [1]. This trend responds to the global problem of growing plastic waste, which is stimulated by the growing awareness of consumers, producers and governments. It is estimated that we are currently consuming oil at an unsustainable rate, and to alleviate these problems, governments in many countries are enacting laws that encourage the use of recycled, renewable and biodegradable polymers [2]. The new sustainable platform of the Institute for European Environmental Policy (IEEP) is Think 2030, which will direct EU member states towards the circular economy of plastic products [3].

The primary disadvantage of composite materials is the fact that two different components of the system make their reuse or recycling considerably complicated [4]. Another disadvantage, especially when using traditional reinforcements based on glass, carbon and aramid fibers, is the high energy intensity of their production [5]. In this respect, matrices based on thermoplastic polymers offer the advantage of being able to thermally further recycle and reuse these materials [6]. The most 
common form of recycling of composite materials are methods based on mechanical processing using various grinding methods, where the resulting products are subsequently reused in secondary applications. However, it should be noted that most composites end up mainly in landfills. At present, however, intensive research is also devoted to pyrolysis and solvolysis. Although these are very progressive technologies that are still evolving, their current technological state is considered to be either highly energy intensive or necessitates further chemical and recycling steps [7]. One of the possibilities in how to overcome the above-mentioned environmental shortcomings is to use sustainable composites based on renewable resources. These materials, often called "green" composites, are based on natural fillers and reinforcing elements that use biopolymer matrices from renewable sources [8]. The lower environmental impacts of these materials can be used mainly in applications that do not require excellent mechanical properties (secondary and tertiary structures or consumer goods such as packaging, covers, gardening supplies, etc.) [9].

The most studied biopolymer today is polylactic acid (PLA), which belongs to the family of linear aliphatic polyesters. It is a biocompatible and compostable (industrially biodegradable) thermoplastic polymer, which is obtained primarily by lactide ring opening polymerization. Lactide itself can be made from lactic acid, which is obtained by fermenting glucose or dextrose from renewable sources such as corn, sugar cane or sugar beet using various bacteria [10]. Although PLA exhibits interesting physical and mechanical properties, such as high tensile strength (50-70 MPa) and modulus of elasticity ( $3 \mathrm{GPa}$ ), excellent transparency, good process ability or biodegradability, its low impact strength and slow crystallization, which results in low temperature resistance, limit its use in more advanced technical applications [11]. The second most frequently studied group of biopolymers is polyhydroxyalkanoates (PHA), which also belongs to the group of linear polyesters. They are synthesized as intracellular carbon storage compounds and act as an energy reservoir for bacteria in the absence of food. PHAs are widely used in various biomedical applications due to their excellent biocompatibility and biodegradability [12].

The most important PHAs are poly (3-hydroxybutyrate) (PHB) and poly (3-hydroxybutyrate-co3-hydroxyvalerate) (PHBV). PHB is a highly crystalline and brittle polymer with a high melting point and stiffness. To increase greater flexibility and improve process ability, PHB is copolymerized with 3-hydroxyvalerate (HV). The resulting PHBV is a copolymer of PHB with randomly arranged 3-hydroxybutyrate (HB) groups and 3-hydroxyvalatate (HV) groups [13]. The copolymer shows an increase in elongation at break and at the same time a decrease in the modulus of elasticity, crystallinity and melting point with increasing content of the HV group [14].

Today, it is possible to use natural material not only as composite matrices (biopolymers), but also as natural fibers, thus replacing synthetic fibers. The growing interest in natural fibers is mainly due to their good mechanical properties, low density and biodegradability at the end of their life cycle and low production costs. It follows from the above factors that the price for natural fibers is three times lower than for glass fibers, four times lower than for aramid fibers and five times lower than for carbon fibers [1]. Fibers of plant origin are cell walls found in the stems and leaves of plants. The fiber is an elementary linear structure, has a characteristic longitudinal and transverse cross-section and consists of primary chemical components [2]. The fibers are composed of cellulose, hemicellulose, lignins, aromatics, waxes and other lipids, ash and water-soluble compounds [3]. In this respect, plant natural fibers are an optimized structure, tested by evolution. Compared to glass or carbon fiber processing, natural fibers have a better impact on the environment and safety when using products with natural fibers. The disadvantages are flammability, variable quality and the need for drying.

The incorporation of natural reinforcing fibers into biopolymers can not only reduce the cost of the resulting composites, but also produce composites with a wide range of potential applications with many environmental benefits. The final properties of biocomposites reinforced with natural fibers are influenced by several factors, both from the point of view of fibers and from the point of view of the matrix. From the point of view of the fibers, the degree of filling, the length of the fibers, the morphology of the fibers, the orientation of the fibers and the distribution of the fibers have an effect. From the point 
of view of the biopolymer matrix, the resulting properties will depend on the molecular weight and the processing conditions. Another important parameter in green composites is the adhesion between the hydrophobic matrix and natural fibers, and the even distribution of the fibers [15]. Lignocellulosic fibers are generally hydrophilic and cellulose (microfibrils) is their main structural and reinforcing component [16]. Spirally wound cellulose microfibrils provide strength, stiffness and structural stability to natural fibers. The chemical structure of cellulose, which is responsible for its hydrophilic character, contains three reactive hydroxyl groups $(\mathrm{OH})$. Two of them form hydrogen bonds inside cellulose macromolecules [17].

To improve the compatibility between the hydrophilic fibers and the hydrophobic matrix, various surface treatments using various chemicals have been developed over the years. However, these modifications usually use a large number of solvents [18]. The most commonly used chemical surface treatments for plant fibers include sialylation [19], acetylation [20] or maleic anhydride interfacial compatibilizers [21]. However, the handling and disposal of hazardous chemicals is not environmentally attractive. Alternatively, more environmentally friendly methods involving various physical or biological surface modifications of natural fibers have also been explored in recent years [22]. Among these methods, the plasma treatment of natural fibers is the most interesting from the point of view of industrial applicability, mainly due to short operating times of modification and low operating costs [23]. By plasma modification, various functional groups can be added to the surface of natural fibers, and these functional groups can form stronger covalent bonds with the matrix, leading to a better interfacial interface and increased mechanical properties. In systems using atmospheric plasma, the total plasma density is much higher, which increases the rate and rate of incorporation of ionized molecules into the surface of the material. The fibers then have a higher surface energy. When treating the surface of fibers with low-pressure plasma, there is no mechanical action and the thermal effect on the surface of the fibers is minimal [12]. Additionally, surface etching due to plasma treatment can improve the surface roughness and lead to a better connection to the matrix by means of mechanical locks [18]. The plasma treatment can generate a variety of surface modification effects depending on the ionized gas type, exposure duration, microwave strength and the distance of the fibers from the plasma source. A detailed study of the principles and application of plasma surface modification of natural fibers has been described by Sun and team [24]. In several publications $[23,25,26]$ was, after usage plasma surface treatment, evaluated enhancement of surface adhesion of natural fibers with the PLA matrix, which evoke thermal stability, wettability and mechanical properties enhancing. The influence of dielectric barrier plasma discharge (DBD) on the resulting mechanical properties of biocomposite systems based on PLA/PALF has been investigated in our previous work [27]. A recent study then compared the effect of the content of technical cellulose fibers and their modification by DBD and $\mathrm{O}_{3}$ on the crystallization of PLA biocomposites [28]. Simultaneously, our colleagues recently investigated the possibility of modifying natural fibers by treating the surface with ozone [29], which is a process of oxidizing the surface of natural fibers with a reactive gas that acts as an intense oxidizing agent.

Another interesting and industrially applicable physical approach to improving interfacial adhesion and mechanical properties is the subsequent and additional exposure of manufactured composites to the effects of radiation crosslinking. Radiation crosslinking of polymers is based on the bombardment of molecules by a stream of high-energy electrons or gamma rays. This energy is absorbed by the material, radicals are formed (breakdown of C-H bonds), which gradually react with each other and form the desired connection. As a result of ionizing radiation, linking macromolecular chains emerge and form the spatial grid. The network is thus formed by the gradual joining of two free radicals between adjacent chains to form a $\mathrm{C}-\mathrm{C}$ bond. The irradiation cross-linking of thermoplastic materials is performed separately after processing. Ionizing radiation includes accelerated electrons, gamma rays and $\mathrm{X}$-rays. Gamma rays have a high penetration capacity. These are not only capable of converting monomeric and oligomer liquids, but can also cause major changes in the properties of solid polymers through cross-linking. The cross-linking level can be adjusted by the irradiation dose. From the results of previous studies, it is apparent, that the radiation crosslinking is a very efficient 
method for modifying the final properties of the polymers. However, some knowledge remains unexplained so far, and therefore each new finding about the effect of radiation crosslinking on the mechanical properties and behavioral characterization of polymer materials may contribute to a better understanding of the issue, especially in the field of biopolymer composites.

\section{Materials and Methods}

\subsection{Materials}

Two biopolymer matrices were chosen for the preparation of biocomposites. The first polymer was PLA material designated Ingeo Biopolymer 3251D from NatureWorks LLC (Minnetonka, MN, USA). It is a biopolymer intended for processing by injection molding technology and is standardly supplied in the form of granules. The second polymer was PHBV material Enmat Y1000P from TianAn Biopolymer (China). It is a biopolymer, which, like the PLA material, is supplied in granules and is intended for processing by injection, extrusion, blow molding and thermoforming technologies. The natural filler was technical cellulose (CeF) purchased from Arbocel ZZC 500, J. Rettenmaier \& Söhne (Germany). Producer of technical cellulose declare the average fibers size as a $400 \mu \mathrm{m}$, thickness $45 \mu \mathrm{m}$ and chemical composition: 80-90 mass\% cellulose and 10-20 mass\% calcium carbonate [28]. Microscopic images of the cellulose fibers are shown in Figure 1.

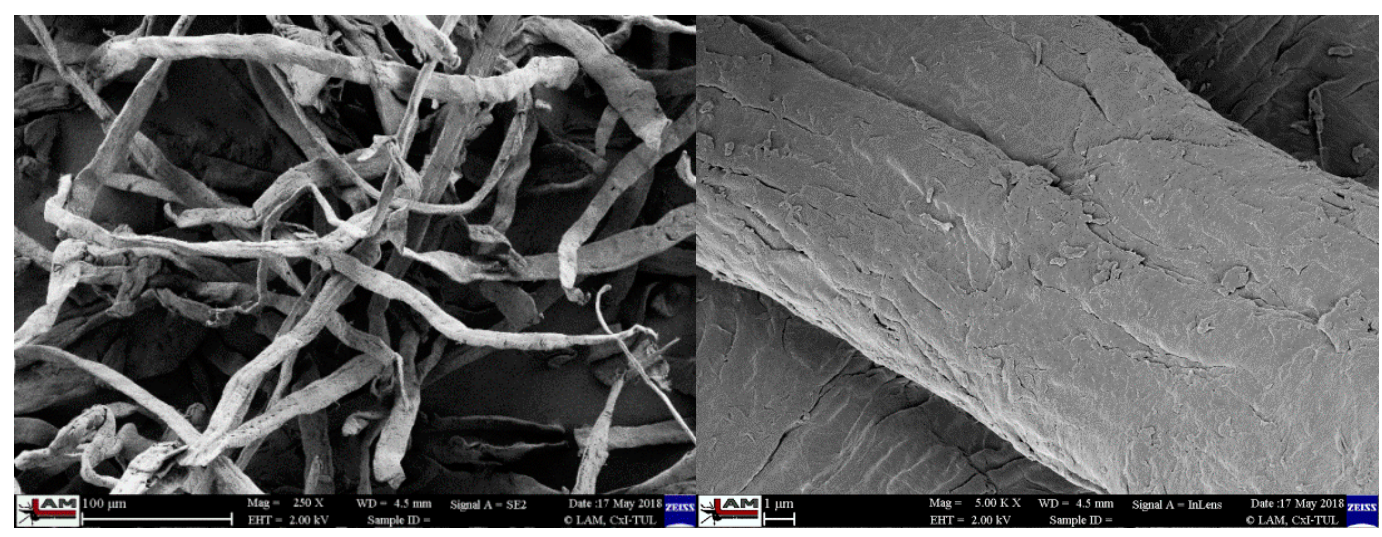

Figure 1. Microscopic image of cellulose fibers.

Modification of biocomposite systems (matrix $+\mathrm{CeF}$ ) and physical and chemical modification of the surface of cellulose fibers were used to influence the final properties of biocomposite materials. The radiation crosslinking method on the BGS Beta-Gamma-Service GmbH and Co. (Germany) plant was used to modify biopolymer composite systems with a PLA and PHBV matrix with two different doses of gamma radiation 50 and $100 \mathrm{kGy}$ (signification R). Both physical (plasma and ozone) and chemical processes (acetylation) were used for surface modification of cellulose fibers. The MSV Systems CZ device was used for plasma modification (signification P) of cellulose fibers, enabling low-temperature plasma technology, consisting of two parallel electrodes covered with a $1 \mathrm{~mm}$ layer of dialectic, between which a volumetric cold plasma discharge burned in the filament mode. The electrodes were rectangular in size $50 \mathrm{~mm} \times 60 \mathrm{~mm}$ with a thickness of $8 \mathrm{~mm}$ without active cooling and the distance between the electrodes was $15 \mathrm{~mm}$. Plasma modification of cellulose fibers (see Figure 2a) was performed under the following conditions: voltage $20 \mathrm{kV}$, frequency 3 to $10 \mathrm{kHz}$, and power $200 \mathrm{~W}$. From the acetylation point of view (signification A), the cellulose fibers were soaked in a reaction bath having the following composition: $85 \mathrm{~g}$ of acetic anhydride, $1 \mathrm{~g}$ of sulfuric acid, and $914 \mathrm{~g}$ of concentrated acetic acid. The cellulose fibers were soaked in a bath in a closed vessel for $24 \mathrm{~h}$ at a bath temperature of $20^{\circ} \mathrm{C}$. Subsequently, rinsing was performed under running water until neutral $\mathrm{pH}$ and finally neutralization was performed with sodium carbonate with a concentration of $1 \mathrm{~g} \cdot \mathrm{L}^{-1}$ (see Figure 2c). The GO 5LAB (Triotech, Czech) apparatus was applied to generate ozone 
(signification $\mathrm{O}$ ) during surface treatments. Natural fillers $(\mathrm{CeF})$ were exposed to dried airflow (dew point $+5{ }^{\circ} \mathrm{C}$, flow rate $3 \mathrm{~L} \mathrm{~min}^{-1}$ ) with a concentration of oxygen nearly $100 \%$ and generation of ozone by $20 \mathrm{mg} \mathrm{L}^{-1}$. Ozone concentration was measured by the UV photometer LF200 (Greisinger, Germany). Elimination of the redundant ozone was ensured in ozone destruction units, which is filled with active carbon. Treating time was $4 \mathrm{~h}$. Additionally, the natural fillers were cleaned in pure airflow for $1 \mathrm{~h}$ to replace the rest of the ozone (see Figure $2 b$ ).

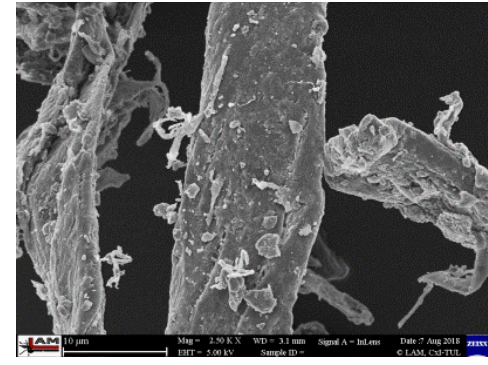

(a)

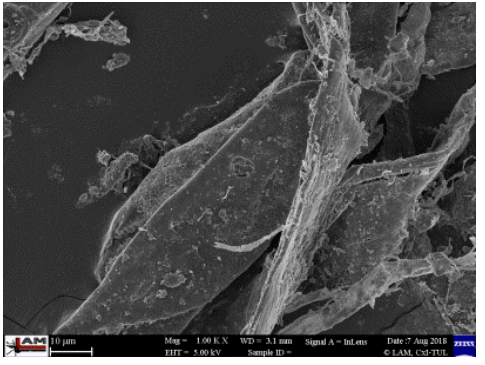

(b)

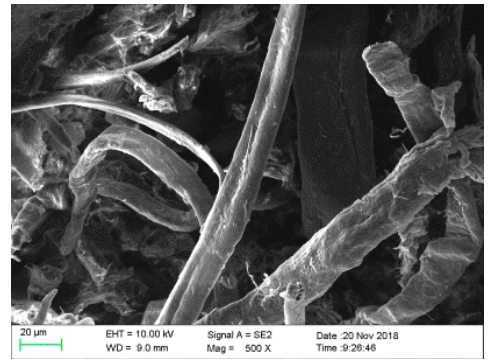

(c)

Figure 2. Microscopic image of cellulose fibers (CeF) after plasma modification (a), after ozonation (b) and acetylation (c), SEM.

\subsection{Preparation of Biopolymer Composites}

For suitable process adjustment, the decomposition temperature of natural filler and its amount of inorganic phase were evaluated before composite production. Thermal degradation has been performed using thermal gravimetric analysis (TGA) on a TGA2 instrument (Mettler Toledo, Greifensee, Switzerland). Samples were heated from 50 to $600{ }^{\circ} \mathrm{C}$ under $\mathrm{N}_{2}$ atmosphere and further from 600 to $800{ }^{\circ} \mathrm{C}$ under $\mathrm{O}_{2}$ atmosphere at the heating ramp of $10{ }^{\circ} \mathrm{C} \mathrm{min}^{-1}$. The initial decomposition temperature was determined at $5 \%$ mass loss. Decomposition of cellulose fibers at $263^{\circ} \mathrm{C}$. The residual mass was evaluated at $800{ }^{\circ} \mathrm{C}$. The evaluated average amount of the inorganic phase (ash) was 13 mass $\%$ in cellulose fibers (see Figure 3a).

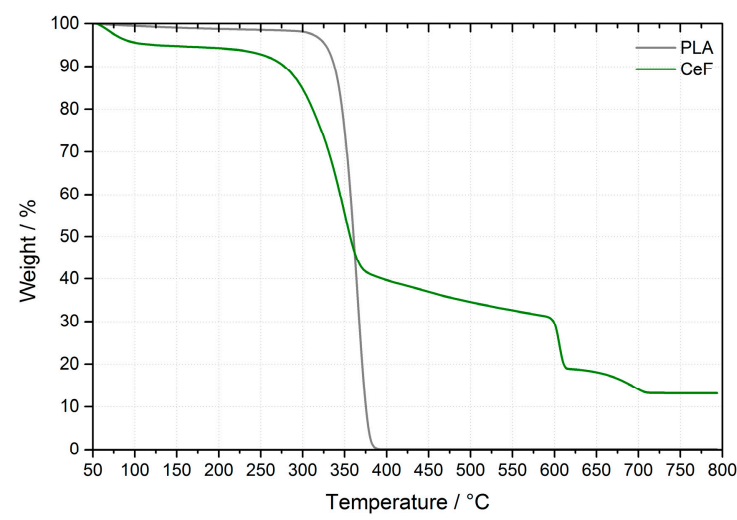

(a)

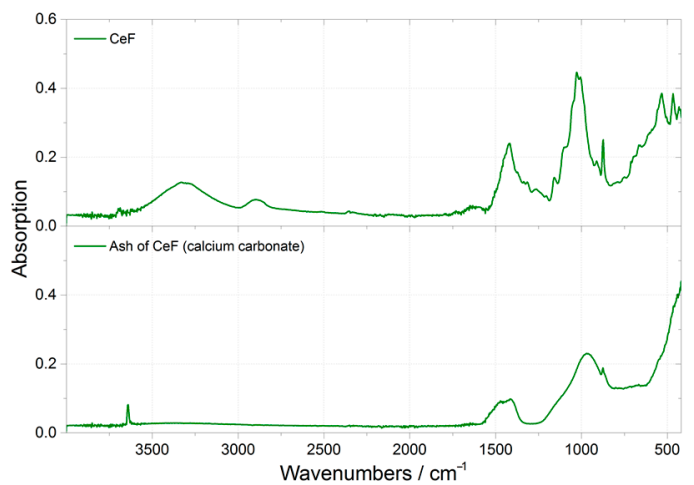

(b)

Figure 3. TG curves of PLA and cellulose fibers (CeF) decomposition (a) and FTIR spectra of cellulose fibers $(\mathrm{CeF})$ before and after thermal decomposition $(\mathbf{b})$.

The chemical composition of the ash was determined by Fourier transform infrared spectroscopy (FTIR), at ambient temperature $\left(23^{\circ} \mathrm{C}\right)$. FTIR spectra of cellulose fibers and their ashes were recorded using a Nicolet iS10 FTIR spectrometer (Nicolet, Rhinelander, WI, USA) with DLaTGS (deuterated lanthanum $\alpha$ alanine doped triglycine sulfate) detector and diamond attenuated total reflection (ATR). In all cases, a total of 64 scans at a resolution of $4 \mathrm{~cm}^{-1}$ were used to record the spectra. The spectra were taken over a wavenumber range of $400-4000 \mathrm{~cm}^{-1}$ and were obtained with respect to a background, 
which was taken of the air previously and under the same measurement conditions (see Figure 3b). From the FTIR spectra, it can be stated that the ash of the cellulose fibers to calcium carbonate. On the FTIR spectrum of calcium carbonate the fundamental bands can be seen at: $708 \mathrm{~cm}^{-1}$ (in-plane bend), $883 \mathrm{~cm}^{-1}$ (out-of-plane bend) and at about 1400-1500 $\mathrm{cm}^{-1}$ (asymmetric stretch) [30]. The ash of technical cellulose fibers contained the same bands at wavenumbers $875 \mathrm{~cm}^{-1}$ and $1416 \mathrm{~cm}^{-1}$. The results of ash chemical composition correspond to material composition of Arbocel ZZC 500.

Before the processing was polymer PLA and polymer PHBV dried in Maguire Low Pressure Dryer (LPD 100) under the following conditions: temperature $80^{\circ} \mathrm{C}$, time $120 \mathrm{~min}$ and vacuum 0.8 bar to a residual moisture content of $0.025 \%$. Prior to compounding, the natural fibers were dried in a Venticell 222 hot air oven with forced air circulation at a temperature of $80^{\circ} \mathrm{C}$ for $120 \mathrm{~min}$. Biocomposite pellets were prepared by twin screw extruder (ZAMAK EHP-2x130di) followed by water bath and pelletizer. Temperature profile of the extrusion line was set from 160 up to $190^{\circ} \mathrm{C}$ for the polymer PLA and PHBV. Cellulose fibers were dosed directly into the melting chamber of extruder in the recommended front position by the external device, working on the gravimetric principle. The reason for dosing in the front parts of the extruder is to prevent excessive shear stress of cellulose fibers during melt compounding and thus their damage or thermal degradation. Pelletized compounds PLA and PHBV passed through a water bath and thus were before injection molding dried at the Maguire Low Pressure Dryer (LPD 100) under following conditions: temperature $80^{\circ} \mathrm{C}$, time $180 \mathrm{~min}$ and vacuum 0.8 bar. A total of 12 biocomposite materials were compared for the same percentage volume of natural fillers in the matrix (20 wt\% cellulose fibers) with different type of matrix (PLA and PHBV), different type of surface modification of fibers (plasma modification, ozonation and acetylation) and different value of gamma radiation (50 and $100 \mathrm{kGy}$ ), which were compared with a pure unfilled biopolymer matrix of PLA and PHBV (see Table 1). Testing specimens were injection molded according to ISO 527 and ISO 178 on the injection molding machine (ARBURG 270S 400-100) with increasing temperature profile (165-190 ${ }^{\circ} \mathrm{C}$ for the polymer PLA and $160-180{ }^{\circ} \mathrm{C}$ for the polymer PHBV) of the melting chamber and injection speed $35 \mathrm{~cm}^{3} \cdot \mathrm{s}^{-1}$ for PLA and injection speed $25 \mathrm{~cm}^{3} \cdot \mathrm{s}^{-1}$ pro PHBV. Resulted biocomposites and control samples are depicted in Table 1.

Table 1. PLA and PHBV biopolymer composites samples.

\begin{tabular}{|c|c|c|c|c|c|}
\hline \multirow{2}{*}{ Sample Code } & \multirow{2}{*}{$\begin{array}{c}\text { Type of } \\
\text { Biopolymer }\end{array}$} & \multicolumn{2}{|c|}{ Composition (wt $\%$ ) } & \multirow{2}{*}{$\begin{array}{c}\text { Modification } \\
\text { of Fibers }\end{array}$} & \multirow{2}{*}{$\begin{array}{l}\text { Modification } \\
\text { of Composite }\end{array}$} \\
\hline & & Biopolymer & Cellulose Fibers & & \\
\hline PLA & PLA & 100 & 0 & No & No \\
\hline PLA-20CeF & PLA & 80 & 20 & No & No \\
\hline PLA-20CeF-P & PLA & 80 & 20 & Plasma & No \\
\hline PLA-20CeF-O & PLA & 80 & 20 & Ozone & No \\
\hline PLA-20CeF-A & PLA & 80 & 20 & Acetylation & No \\
\hline PLA-20CeF-R50 & PLA & 80 & 20 & No & Radiation \\
\hline PLA-20CeF-R100 & PLA & 80 & 20 & No & Radiation \\
\hline PHBV & PHBV & 100 & 0 & No & No \\
\hline PHBV-20CeF & PHBV & 80 & 20 & No & No \\
\hline PHBV-20CeF-P & PHBV & 80 & 20 & Plasma & No \\
\hline PHBV-20CeF-O & PHBV & 80 & 20 & Ozone & No \\
\hline PHBV-20CeF-A & PHBV & 80 & 20 & Acetylation & No \\
\hline PHBV-20CeF-R50 & PHBV & 80 & 20 & No & Radiation \\
\hline PHBV-20CeF-R100 & PHBV & 80 & 20 & No & Radiation \\
\hline
\end{tabular}

\subsection{Methods}

\subsubsection{Uniaxial Tensile Testing}

For tensile testing of injection molded specimens a Tiratest 2300 were used. The measurement was performed according to the STN EN ISO 527 standards with the tested specimen $1 \mathrm{~A}$. The specimens were strained at room temperature up to break at a test speed $5 \mathrm{~mm} \cdot \mathrm{min}^{-1}$. The module of tensile elasticity 
(Young's modulus) was determined at a reduced test speed $1 \mathrm{~mm} \cdot \mathrm{min}^{-1}$. From the stress-strain dependences, tensile strength was calculated. The measurement was performed on 10 test specimens at a temperature of $23^{\circ} \mathrm{C}$. The mean value and standard deviation were calculated. The conditioning took place in conditions according to STN EN ISO 291. The LabNet program was used for the evaluation.

\subsubsection{Flexural Testing}

The bending test (according to STN EN ISO 178) was measured on a Hounsfield H10KT tearing machine. The conditioning was performed according to the STN EN ISO 291 standard. Test specimens measuring $80 \mathrm{~mm} \times 10 \mathrm{~mm} \times 4 \mathrm{~mm}$ were placed on two supports. To determine the modulus of elasticity, the measurement was performed at a speed of $2 \mathrm{~mm} \cdot \mathrm{min}^{-1}$ with preload according to the standard. Measurements were made on 10 test specimens at $23^{\circ} \mathrm{C}$ and the mean and standard deviation were calculated. The measured values were recorded by the Qmat program. For the secant modulus, it was necessary to determine the stress $\left(\sigma_{f 2}\right.$ and $\left.\sigma_{f 1}\right)$ at a relative elongation of $0.05 \%\left(\varepsilon_{f 1}\right)$ and $0.25 \%$ $\left(\varepsilon_{f 2}\right)$, respectively. The modulus of elasticity itself was then calculated based on Equation (1):

$$
E_{f}=\frac{\sigma_{f 2}-\sigma_{f 1}}{\varepsilon_{f 2}-\varepsilon_{f 1}}
$$

where $E_{f}$ is the secant modulus, $\sigma_{f 2}$ is the stress at relative elongation $0.25 \%, \sigma_{f 1}$ is the stress at relative elongation $0.05 \%, \varepsilon_{f 2}$ is the relative elongation $0.25 \%$ and $\varepsilon_{f 1}$ is the relative elongation $0.05 \%$.

\subsubsection{Charpy Impact}

The Charpy method according to the STN EN ISO 179-1 standard on the Resil 5.5 device was used to determine the impact strength. Prior to the actual measurement, the instrument was calibrated for mechanical resistance and air resistance at "idle" start-up. The conditioning was performed according to the STN EN ISO 291. The test specimens had dimensions of $80 \mathrm{~mm} \times 10 \mathrm{~mm} \times 4 \mathrm{~mm}$. The measurement was performed on 10 test specimens at a temperature of $23^{\circ} \mathrm{C}$. After the measurement, the impact toughness $\mathrm{a}_{\mathrm{CU}}$ was calculated and the mean value and standard deviation were calculated from the values.

\subsubsection{Scanning Electron Microscopy (SEM)}

Scanning electron microscopy was used to determine a fracture surface analysis in the central part of test specimens of biocomposites with natural cellulose fibers without modification of the fiber surface, with the modification of the fiber surface and for samples after radiation crosslinking. The scanning electron microscope (SEM) was conducted on Carl Zeiss ULTRA Plus (Carl Zeiss, Oberkochen, Germany) at an acceleration voltage range of $2-5 \mathrm{kV}$. The surface of all fracture surfaces was provided with a thin layer of platinum $(3 \mathrm{~nm})$ to improve the conductivity of the samples.

\section{Results and Discussion}

Polymer composites with a biopolymer matrix are increasingly used in practice, and therefore it is very important to have knowledge about composite structures in relation to the possibilities of additional modification of biocomposites as a whole, or in relation to surface modification of the natural filler. The presence of fibers in biopolymer composites and the application of surface modifications of the filler or the prepared composite as a whole should have an impact on the properties and mechanical characterization of composite structures and the behavior of composites under the load.

\subsection{Tensile Properties}

The tensile properties of PLA and PHBV biocomposites are summarized in Figure 4. Figure 4 show not only the negligible effect of adding $20 \%$ cellulose fibers to the biopolymer matrix, but also the negligible effect of surface modification of natural cellulose fibers in both biocomposite systems 
with PLA and PHBV matrix on the tensile modulus. The SEM images show that the adhesion between the natural fibers and the biopolymer matrix at the interfacial interface was less satisfactory, the fibers were not perfectly surrounded by the polymer (see Figure 5). For biocomposite structures with PLA matrix and cellulose fibers without modification and with surface modification of fibers by physical or chemical means (see Figure 4) it was evident that the tensile modulus was almost comparable (differences are in the order of percentage units) and was comparable with the unfilled PLA matrix. Surface modification of cellulose fibers (except plasma treatment) did not affect the increase of the tensile modulus value compared to PHBV matrix or PHBV matrix with unmodified cellulose fibers and the lowest values were reached by PHBV biocomposite with modification of cellulose fibers by acetylation.

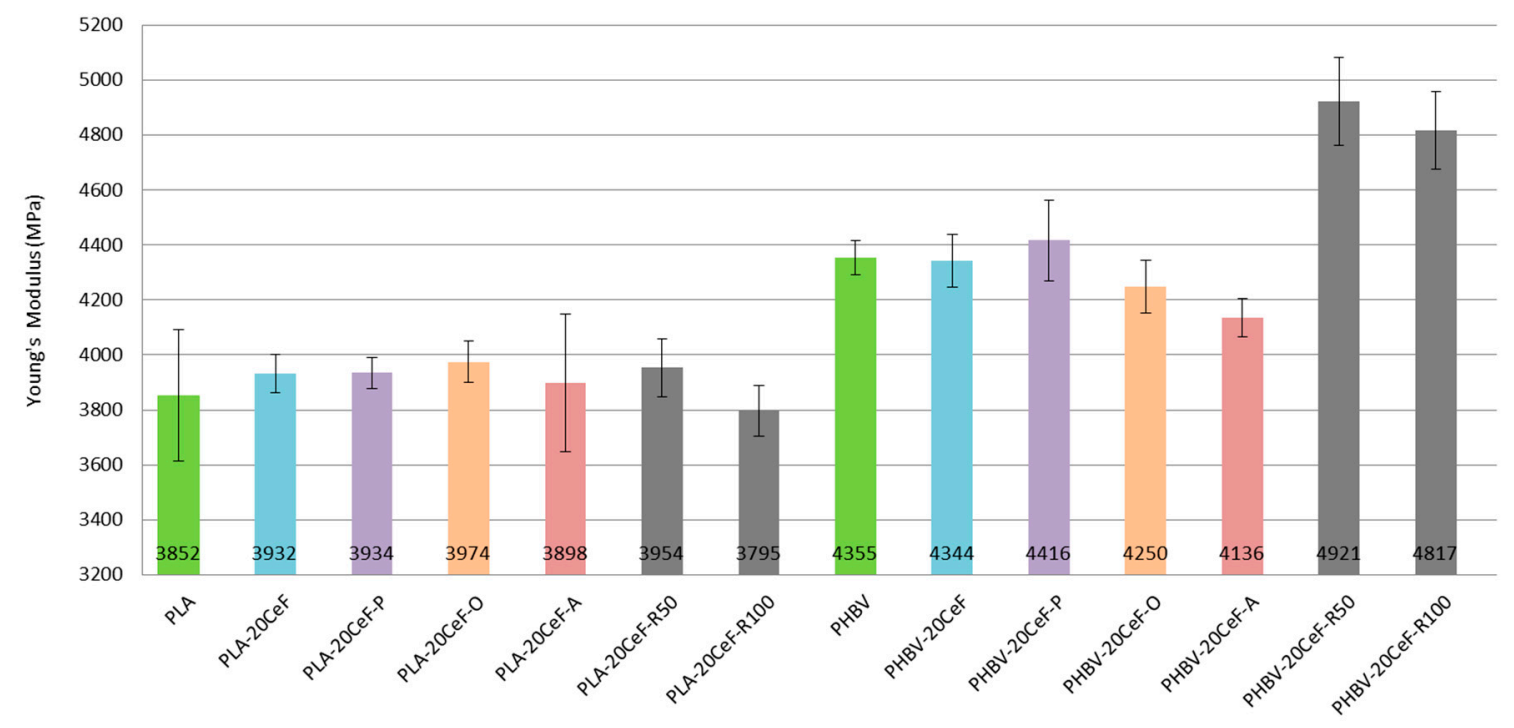

Figure 4. Tensile modulus of elasticity (Young's modulus) of PLA and PHBV biopolymer composites.

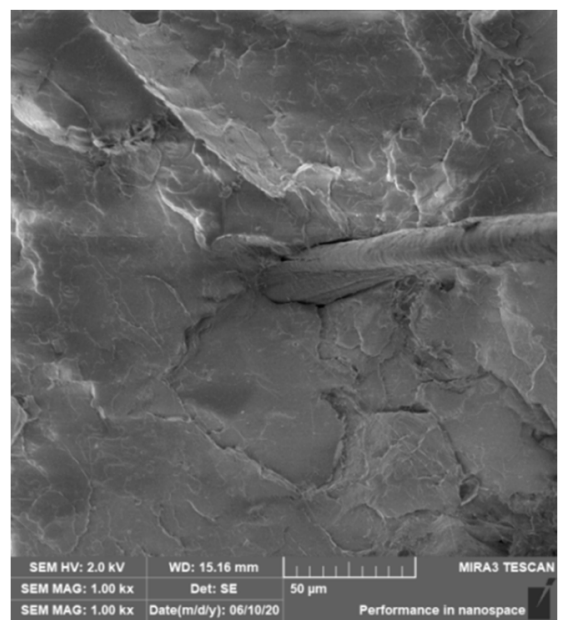

(a)

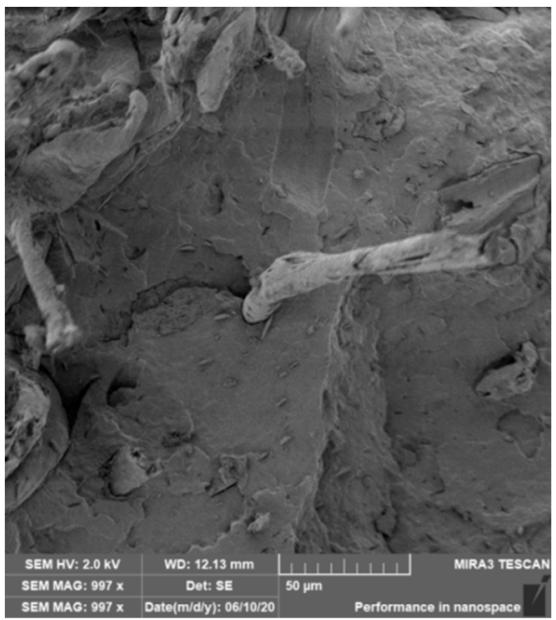

(b)

Figure 5. Microscopic image of fracture surfaces of the biocomposite structure with the PLA matrix and cellulose fibers (CeFs) after application of ozonation (a) and the PHBV matrix after plasma application (b), SEM.

Furthermore, the results show a negative impact of additional radiation crosslinking on the tensile modulus of elasticity of the PLA matrix, which was greater the greater the value of radiation. In contrast, for the PHBV matrix, the use of radiation crosslinking had the opposite effect, the value of the tensile modulus increased (about 15\%), although as with PLA, the increasing radiation value 
decreased the tensile modulus. In the case of the application of radiation crosslinking in PLA composites, the values were comparable both with the unfilled PLA matrix and with biocomposites without and with surface modification of cellulose fibers. In the case of application of twice the radiation value (100 kGy) during radiation crosslinking, the tensile modulus of PLA composite structures reached the lowest value. During radiation crosslinking, the dominant phenomenon of PLA and PHBV biomaterials was the cleavage of ester groups into mainly hydroxyl groups [31]. It was clear from the experimental measurements that with increasing radiation levels, the modulus of elasticity decreased for biocomposites based on the PLA matrix. The degree of crystallinity $\left(\mathrm{X}_{\mathrm{c}}\right)$ of the biopolymer composite PLA increased after the addition of $20 \mathrm{wt} \%$ of CeF fibers. For the neat PLA matrix, the degree of crystallinity was $10.3 \%$, for PLA composites, the $X_{c}$ increased approximately by $5 \%$. Additional radiation crosslinking of PLA composites did not increase the crystallinity degree. Radiation crosslinking caused the scission of internal macromolecular bonds and formation of free radicals. These subsequently reacted and formed a three-dimensional structure by joining two free radicals between adjacent chains. Crosslinking reactions in PLA polymers mainly affected amorphous regions or less crystalline regions in the structure, which as reflected in a decrease in mechanical properties. These results correspond to the results of the work of S. Tiptikorn and the team [32]. The different crystallinity of PLA and PHBV biocomposites resulted in non-identical effect of gamma radiation on the tensile modulus of elasticity (see Tables 2 and 3). The mentioned cleavage of "took place" chains occurs mainly in irradiated amorphous regions [33]. Therefore, it can be assumed that a biopolymer with a higher content of the crystalline phase (see Table 3) was characterized by a higher resistance to radiation and thus a lower decrease in mechanical properties [34]. However, scissions in the linked molecules are the ones that causes the highest losses in mechanical properties to a crystalline polymer [35].

Table 2. Differential scanning calorimetry (DSC) results of PLA biopolymer composites samples.

\begin{tabular}{|c|c|c|c|c|c|c|c|}
\hline $\begin{array}{l}\text { Sample Code } \\
\text { (First Heating) }\end{array}$ & $\begin{array}{l}\text { Temperature } \\
\text { of Cold } \\
\text { Crystallization } \\
\left({ }^{\circ} \mathrm{C}\right) \mathrm{T}_{\mathrm{p}, \mathrm{cc}}\end{array}$ & $\begin{array}{l}\text { Enthalpy of } \\
\text { Cold } \\
\text { Crystallization } \\
(\mathrm{J} / \mathrm{g}) \Delta \mathrm{H}_{\mathrm{cc}}\end{array}$ & $\begin{array}{l}\text { Temperature } \\
\text { of Premelt } \\
\text { Crystallization } \\
\left({ }^{\circ} \mathrm{C}\right) \mathrm{T}_{\mathrm{p}, \mathrm{pc}}\end{array}$ & $\begin{array}{l}\text { Enthalpy of } \\
\text { Premelt } \\
\text { Crystallization } \\
(\mathrm{J} / \mathrm{g}) \Delta \mathrm{H}_{\mathrm{pc}}\end{array}$ & $\begin{array}{l}\text { Melting } \\
\text { Temperature } \\
\left({ }^{\circ} \mathrm{C}\right) \mathrm{T}_{\mathrm{p}, \mathrm{m}}\end{array}$ & $\begin{array}{l}\text { Enthalpy } \\
\text { of Melting } \\
(\mathrm{J} / \mathrm{g}) \Delta \mathrm{H}_{\mathrm{m}}\end{array}$ & $\begin{array}{l}\text { Degree of } \\
\text { Crystallinity } \\
(\%) X_{c}\end{array}$ \\
\hline PLA & 103.2 & -30.30 & 156.7 & -0.81 & 171.7 & 40.74 & 10.3 \\
\hline PLA-20CeF & 97.4 & -27.52 & 155.7 & -2.54 & 171.7 & 41.74 & 15.7 \\
\hline PLA-20CeF-P & 97.7 & -25.60 & 155.9 & -2.44 & 171.3 & 41.70 & 18.3 \\
\hline PLA-20CeF-O & 97.5 & -28.16 & 155.9 & -2.56 & 171.7 & 40.67 & 13.4 \\
\hline PLA-20CeF-A & 96.8 & -26.43 & 154.2 & -2.41 & 169.1 & 39.09 & 13.8 \\
\hline PLA-20CeF-R50 & 98.6 & -28.58 & 154.3 & -1.25 & 167.6 & 42.92 & 17.6 \\
\hline PLA-20CeF-R100 & 98.9 & -32.10 & & & 165.9 & 43.67 & 15.5 \\
\hline
\end{tabular}

Table 3. Differential scanning calorimetry (DSC) results of PHBV biopolymer composites samples.

\begin{tabular}{|c|c|c|c|c|c|c|}
\hline $\begin{array}{l}\text { Sample Code } \\
\text { (First Heating) }\end{array}$ & $\begin{array}{l}\text { Melting } \\
\text { Temperature } \\
\left({ }^{\circ} \mathrm{C}\right) \mathrm{T}_{\mathrm{p}, \mathrm{m} 1}\end{array}$ & $\begin{array}{l}\text { Melting } \\
\text { Temperature } \\
\left({ }^{\circ} \mathrm{C}\right) \mathrm{T}_{\mathrm{p}, \mathrm{m} 2}\end{array}$ & $\begin{array}{c}\text { Enthalpy of } \\
\text { Melting (J/g) } \\
\Delta H_{m}\end{array}$ & $\begin{array}{l}\text { Enthalpy of } \\
\text { Melting (J/g) } \\
\Delta \mathrm{H}_{\mathrm{m} 1}\end{array}$ & $\begin{array}{c}\text { Enthalpy of } \\
\text { Melting (J/g) } \\
\Delta \mathrm{H}_{\mathrm{m} 2}\end{array}$ & $\begin{array}{l}\text { Degree of } \\
\text { Crystallinity } \\
\quad(\%) X_{c}\end{array}$ \\
\hline PHBV & 177.4 & 177.4 & 93.45 & & & 63.7 \\
\hline PHBV-20CeF & 171.7 & 174.3 & 82.48 & 59.88 & 22.60 & 70.3 \\
\hline PHBV-20CeF-P & 171.9 & 174.9 & 82.85 & 69.66 & 13.19 & 70.6 \\
\hline PHBV-20CeF-O & 171.0 & 174.7 & 82.00 & 69.88 & 12.12 & 69.9 \\
\hline PHBV-20CeF-A & 172.7 & 177.0 & 84.95 & 71.52 & 13.43 & 72.4 \\
\hline PHBV-20CeF-R50 & 169.9 & 176.1 & 86.65 & 71.36 & 15.29 & 73.9 \\
\hline PHBV-20CeF-R100 & 169.3 & 174.7 & 82.71 & 71.51 & 11.20 & 70.5 \\
\hline
\end{tabular}

The increase in the tensile modulus of the PHBV biocomposite can be explained by the fact that the cleavage of the amorphous regions was eliminated by increasing the crystal structure of the PHBV biocomposite (see Table 3) after application of gamma radiation. The radiation probably caused the uncontrolled decay of large crystals, which subsequently served as nucleation nuclei for the formation of new crystalline formations [34]. Evidence of the influence of gamma radiation on the change of the crystal structure and on the modulus of elasticity in tension is also given in the studies of L. M. Oliver and colleagues [34,35], where the modulus of elasticity in tension remained almost unchanged even at $100 \mathrm{kGy}$. 
From the results of tensile stress at the yield point (see Figure 6) it can be stated that for biocomposite structures with PLA matrix and cellulose fibers without modification and with surface modification of fibers by the physical or chemical way the values decreased to $65-70 \%$ of the yield stress value for a pure PLA matrix. The effect of the type of surface modification of the cellulose fibers was comparable to each other between the methods used. The effect of the surface treatment of cellulose fibers led to a slight increase in the value of tension compared to unmodified fibers. This may be due to the length of the fibers (the cellulose fibers used were short), the agglomeration of the fibers and also the imperfect adhesion of the fibers to the polymer matrix. Theoretically, continuous fibers would be able to have a significant positive effect, which would be able to transfer the inserted load. However, the situation was significantly different for the PHBV matrix, because for biocomposites without modification of cellulose fibers and with surface modification of fibers by physical or chemical means, the yield stress values were comparable to the pure PHBV matrix. The effect of any surface modification of cellulosic fibers used improved the yield stress values over non-surface modified fibers. After the application of radiation crosslinking to PLA biocomposites, the reduction of the yield strength value was even more pronounced, and by increasing the value of the radiation magnitude, the stress was halved. In PLA, there was a significant degradation of the polymer matrix due to its chemical composition. The higher the energy supplied, the deteriorating the properties, the more likely the chains are shortened or the molecular weight is reduced. The die then does not withstand tensile loading because it had become brittle. After the application of radiation crosslinking in the PLA biocomposite, the decrease compared to the pure PLA matrix was $65 \%$ at a radiation value of $50 \mathrm{kGy}$ and more than $80 \%$ at a radiation value of $100 \mathrm{kGy}$. If we compared the biocomposite structure of PLA with $20 \%$ of cellulose fibers without radiation crosslinking and with radiation crosslinking, then the loss of stress value was $50 \%$ for a radiation value of $50 \mathrm{kGy}$ and $75 \%$ for a radiation value of $100 \mathrm{kGy}$. Increasing the value of radiation from $50 \mathrm{kGy}$ to the value of radiation $100 \mathrm{kGy}$ during radiation crosslinking will reduce the value of tensile stress at the yield point by half. With higher levels of radiation, there was a higher level of chain cleavage and consequent decrease in molecular weight, decrease in glass transition temperature and decrease in mechanical and other properties [36]. The same dependence was detected in the work of L. Meihua and his team [37], who studied the effect of radiation crosslinking of PLA polymer containing "ballast fiber". Additionally, in the works of S. Dadbin and his team [38,39] there was a significant decrease in "tensile strength" with increasing radiation levels.

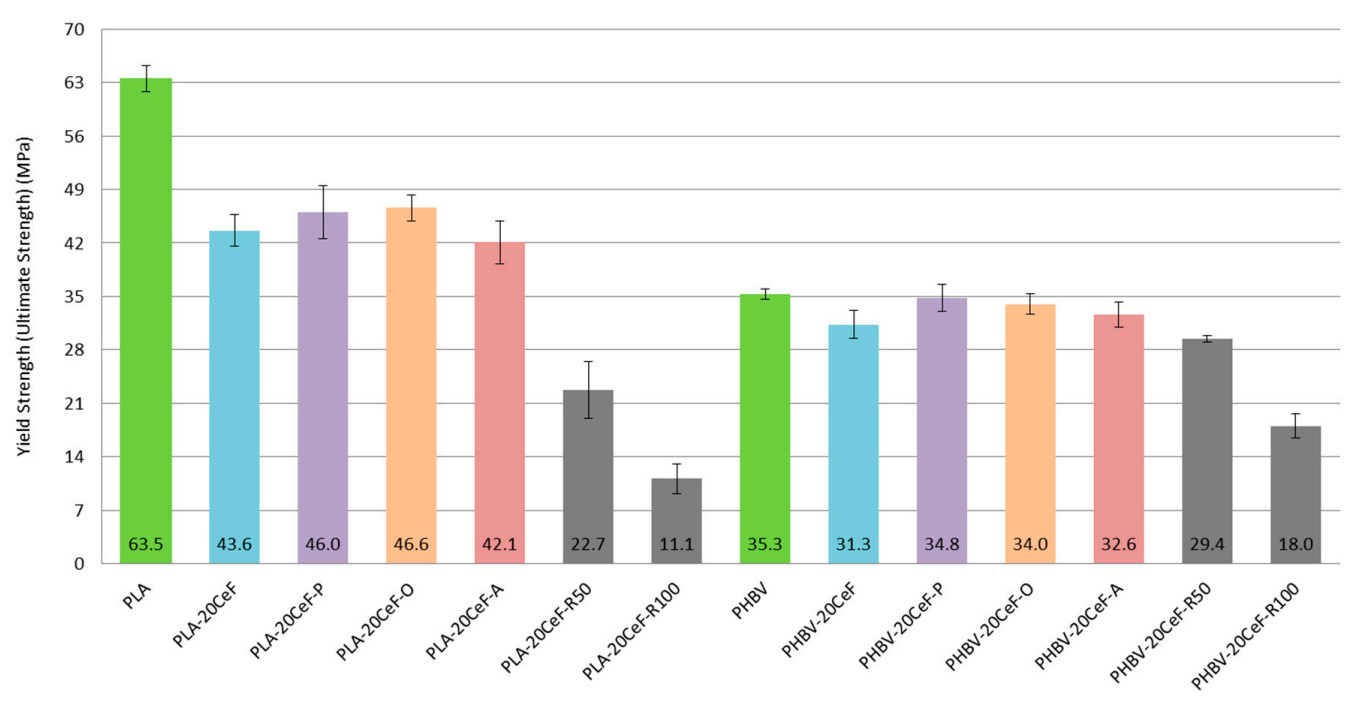

Figure 6. Yield strength (ultimate strength) of PLA and PHBV biopolymer composites.

For PHBV composites, the stress values for the low radiation value were slightly lower compared to the modified fibers and further decreased with increasing radiation value. However, the decrease in yield stress values was much smaller than for PLA biocomposites. PHBV did not appear to have 
such significant degradation of the polymer matrix due to its chemical composition. When applying radiation crosslinking of a biocomposite with a PHBV matrix, the decrease in the voltage value compared to a pure PHBV biopolymer matrix was $15 \%$ for a radiation value of $50 \mathrm{kGy}$ and $50 \%$ for a radiation value of $100 \mathrm{kGy}$. If, as with the PLA matrix, we compared the biocomposite structure of PHBV with $20 \%$ of cellulose fibers without radiation crosslinking and with radiation crosslinking, then the yield stress value was reduced by $5 \%$ at a radiation value of $50 \mathrm{kGy}$, respectively by more than $40 \%$ at a radiation value of $100 \mathrm{kGy}$. By applying radiation crosslinking and doubling the value of the radiation, it led to a decrease in the tensile stress at the yield point by $40 \%$. From the point of view of the matrix used (PLA or PHBV) it was clear from the results that the application of radiation crosslinking of biocomposite structures was a huge loss of properties for biocomposites with the PLA matrix (50 and 75\%), but with the PHBV matrix it was much less negative (5\% and $40 \%$ ). This fact can be explained by the different chemical composition and the influence of gamma radiation on the structure [33]. The results show a decrease in properties, which was more pronounced in comparison with the level of modulus of elasticity in tension. The obtained results are in accordance with the results reported in the works of L.M. Oliver and team [34,35] and the study of S. Luo and team [33], which showed a significant decrease in "tensile strength" when applying gamma radiation.

From the results of the nominal strain at the yield point (see Figure 7), it can be concluded that using cellulose fiber surface modification methods, the nominal strain value of biocomposite structures with a PLA matrix was reduced by about $50 \%$ compared to a pure PLA matrix. In the case of biocomposite systems with a PHBV matrix, the values of the relative elongation were approximately comparable, they only decreased with the application of radiation crosslinking with a high value of radiation. When using radiation crosslinking in PLA biocomposite structures, the decrease in the value of the relative elongation of $70 \%$ relative to the PLA matrix, respectively $40 \%$ compared to PLA composites without and with surface modification of natural cellulose fibers. For a radiation size of $100 \mathrm{kGy}$, the decrease was $80 \%$ respectively $65 \%$. For PHBV biocomposite structures, the changes in values were about half. For a radiation value of $50 \mathrm{kGy}$, the decrease was $25 \%$, resp. $10 \%$ and for a radiation value of $100 \mathrm{kGy}$ there was a decrease of $55 \%$, resp. $45 \%$. Based on the values found, it can be stated that the addition of cellulose fibers decreased the ductility of the biocomposite system (especially for PLA matrix) and with the use of radiation crosslinking and with increasing gamma radiation the relative elongation decreased significantly. Increasing the radiation value from 50 to $100 \mathrm{kGy}$ led to a decrease in ductility by almost $50 \%$ for both biopolymer matrices. Elongation decreased due to the fibrous filler, because due to their morphology they could not transfer the inserted load. The ductility of the matrix was lower after radiation crosslinking, as the structure was degraded due to chain shortening, which was caused by the energy supplied to the system.

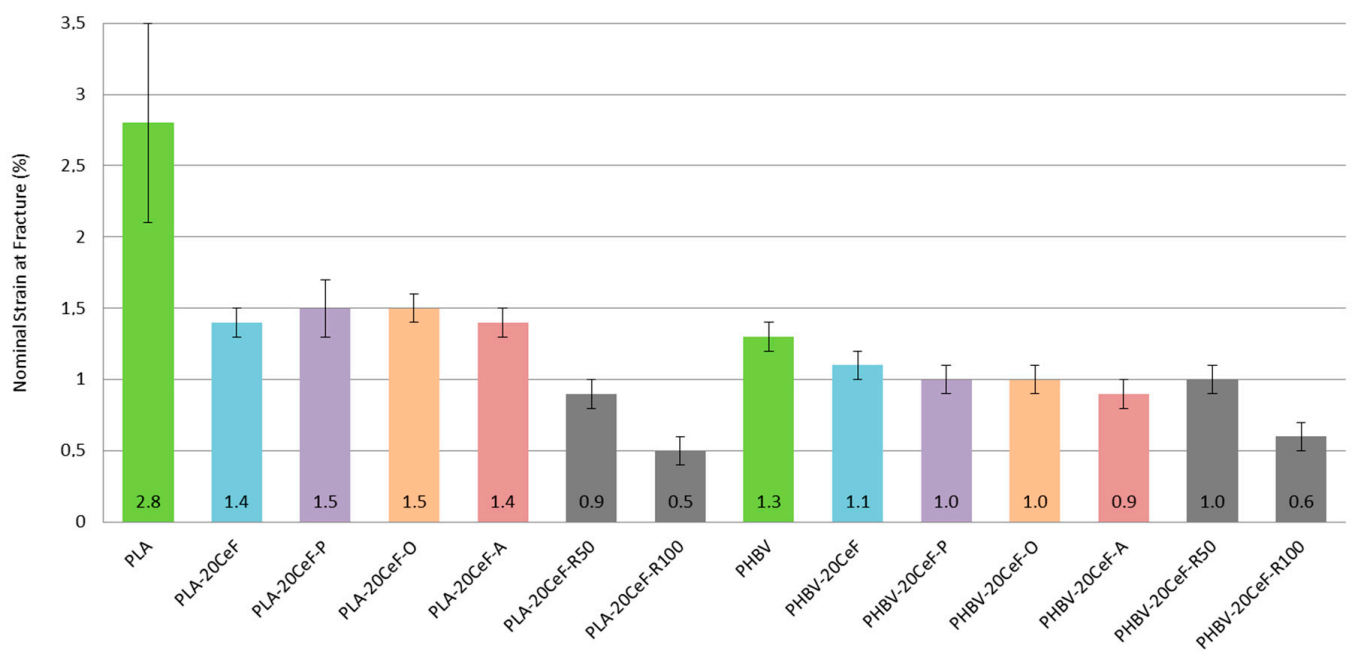

Figure 7. Nominal strain at fracture of PLA and PHBV biopolymer composites. 


\subsection{Flexural Properties}

Based on the flexural test performed it can be concluded that the flexural modulus (see Figure 8) did not substantially increase with the addition of cellulose fibers and fiber modifications to the PLA biopolymer matrix. A significant increase in the flexural modulus occurred only with the PHBV biopolymer matrix. This applies both to the application of radiation crosslinking and to the application of surface modification of cellulose fibers in both physical and chemical ways. This conclusion was confirmed by the fracture surfaces of biocomposite structures, which show significantly improved adhesion at the interfacial interface of the PHBV biopolymer matrix and natural cellulose fibers.

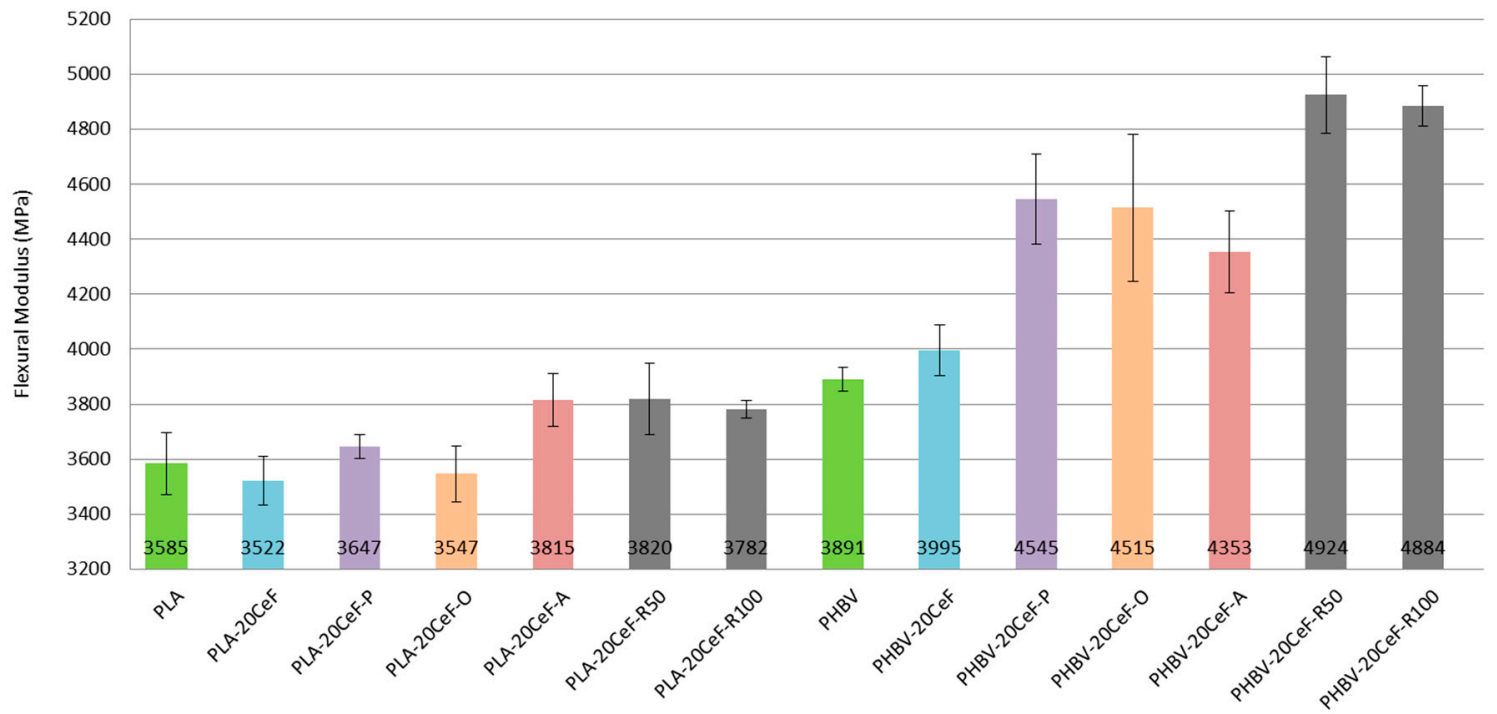

Figure 8. Flexural modulus of PLA and PHBV biopolymer composites.

The flexural modulus values (see Figure 8) for the PLA biopolymer matrix show that the flexural modulus was comparable for almost all samples (pure PLA, unmodified cellulose fibers, surface modified cellulose fibers and radiation crosslinking). Adhesion at the interfacial interface in PLA composites was insufficient (see Figure 9). The modulus of elasticity generally did not change substantially when using fiber fillers without good interfacial adhesion.

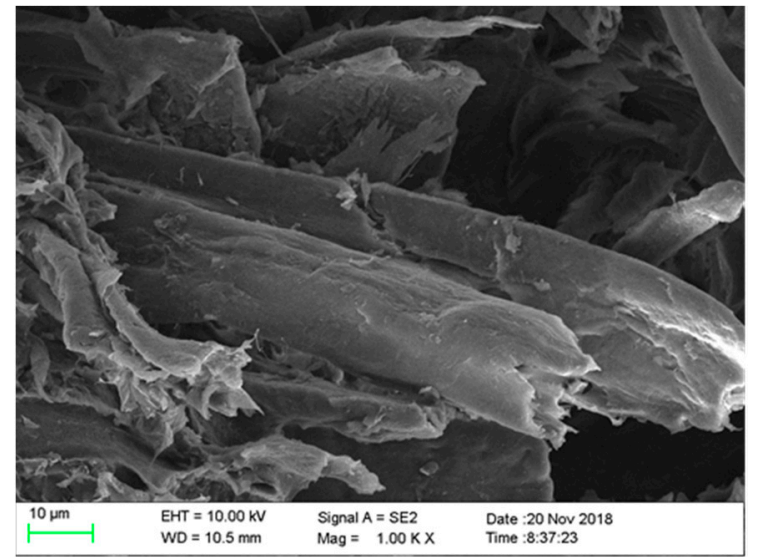

(a)

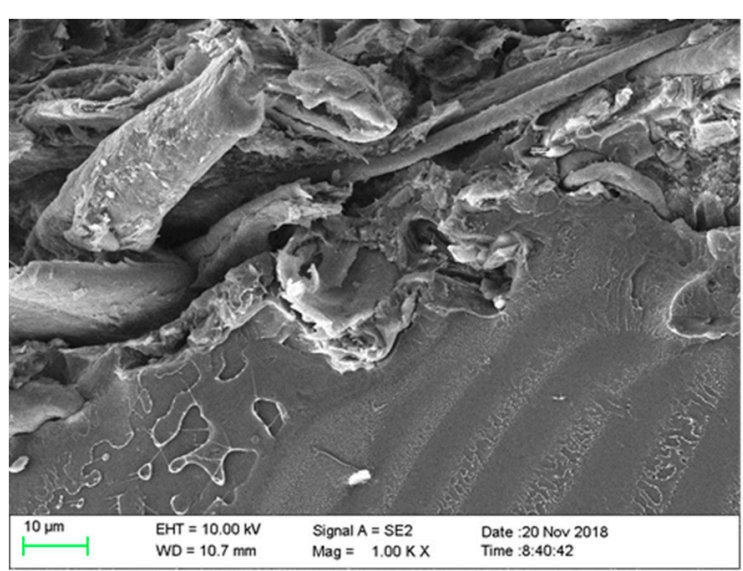

(b)

Figure 9. Microscopic image of fracture surfaces of biocomposite structure PLA with cellulose fibers (CeF) with acetylation (a) and after radiation crosslinking $50 \mathrm{kGy}(\mathbf{b}), \mathrm{SEM}$.

In contrast, in the case of a biocomposite structure with a PHBV matrix, the flexural modulus increased by about $15 \%$ after application of surface modifications of the fibers, where the adhesion was 
significantly better (see Figure 10). While in the biocomposite structure of PHBV without modification of the surface of the cellulose fibers the fracture surface was not homogeneous and dark spots were visible, cavities after fiber extraction, adhesion had improved after surface modification, the matrix coated the fiber reinforcement and cellulose fibers were broken. After the application of radiation crosslinking, the flexural modulus increased by a quarter, $25 \%$ compared to unmodified cellulosic fibers. This was despite the fact that the adhesion at the interface between the matrix and the fibers was minimally affected, but rather the bonds in the polymer matrix were affected, which could occur due to the energy supply to the system and change of morphological system (increase in molecular weight). The effect of the increased radiation value had a negligible effect on the change in the flexural modulus.

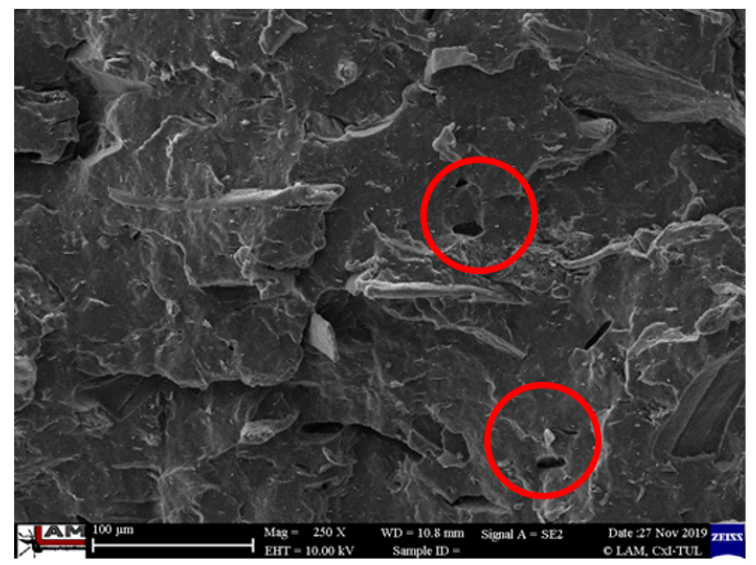

(a)

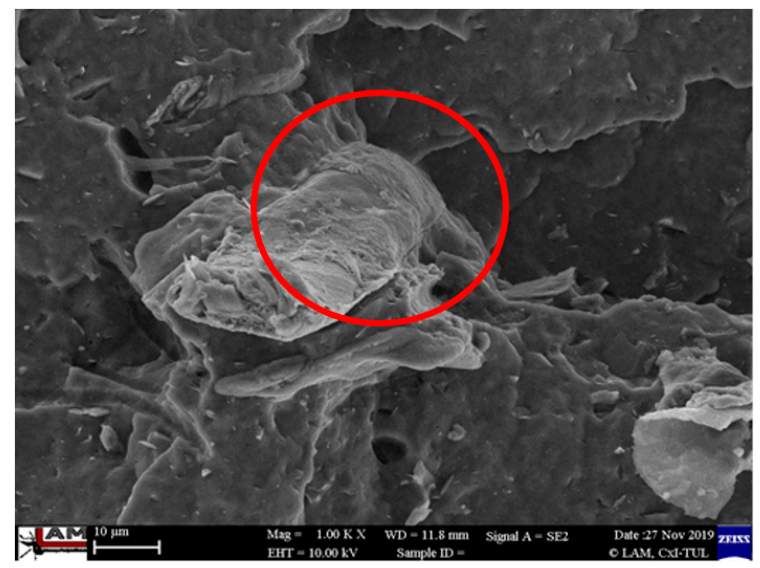

(b)

Figure 10. Microscopic image of fracture surfaces of the PHBV biocomposite structure with cellulose fibers $(\mathrm{CeF})$ without surface modification (a) and after ozonation (b), SEM.

The flexural strength (see Figure 11) of PLA and PHBV biocomposite structures shows similar dependences as the yield strength. In the case of PLA biocomposite with uncoated fibers and surface-modified fibers, the values obtained were always lower than in the case of unfilled PLA; the values decreased to about $80 \%$ of the stress value of the pure PLA matrix. The effect of the type of surface modification of the cellulose fibers was comparable to each other between the methods used. Short cellulose fibers cannot sufficiently contribute to increasing the flexural or tensile strength limit if interfacial adhesion is not sufficient. Additionally, after the application of radiation crosslinking, the values of the flexural strength were even lower. The matrix was degraded by radiation crosslinking or by supplying energy to the system. When using radiation crosslinking of a PLA biocomposite, the decrease compared to a pure PLA matrix was $60 \%$ for a radiation value of $50 \mathrm{kGy}$ and $80 \%$ for a radiation value of $100 \mathrm{kGy}$. If we compared the biocomposite structure of PLA with $20 \%$ of cellulose fibers without radiation crosslinking and with radiation crosslinking, the reduction in stress was $50 \%$ for $50 \mathrm{kGy}$ and 75\% for $100 \mathrm{kGy}$, which was half the stress for half the radiation (50 kGy). The reason was the considerable cleavage of the PLA biopolymer chains, which was even more pronounced with increasing levels of gamma radiation. A similar dependence was detected in the work of L. Meihu [37] and in the work of Dadbin and his team [38,39].

In the case of biocomposite systems with a PHBV matrix, the flexural strength values were approximately comparable both in the case of biocomposites with cellulose fibers without modification and in the case of fibers with surface modification by physical or chemical means and began to decrease with increasing radiation value. When applying radiation crosslinking of a biocomposite with a PHBV matrix, the decrease in stress value compared to a pure biopolymer matrix PHBV or a matrix filled with $20 \%$ unmodified cellulose fibers was about $15 \%$ at a radiation value of $50 \mathrm{kGy}$ and $50 \%$ at a radiation value of $100 \mathrm{kGy}$. Modification of a biocomposite system with a PLA matrix by radiation led to the destruction of biopolymer bonds and thus to a significant decrease in values. In the case of the PHBV 
matrix, this occurred only at a high value of gamma radiation (100 kGy). These results confirm the previous conclusions that in the case of PHBV, there was no fundamental and undesired destruction of the polymer structure after radiation crosslinking if the supplied energy was low. The decrease in the flexural strength was not so great due to the higher content of the crystalline structure of PHBV biocomposites and the influence of gamma radiation on the formed structure. This result corresponds to the results of studies by L. M. Olivera [34,35]. At higher levels of gamma radiation, due to the considerable chain splitting, there is also a significant decrease in mechanical properties of the PHBV biocomposite. The negative effect of higher levels of gamma radiation on the decrease of mechanical properties of PHBV composite systems was recorded in the work of K. Iggui [40].

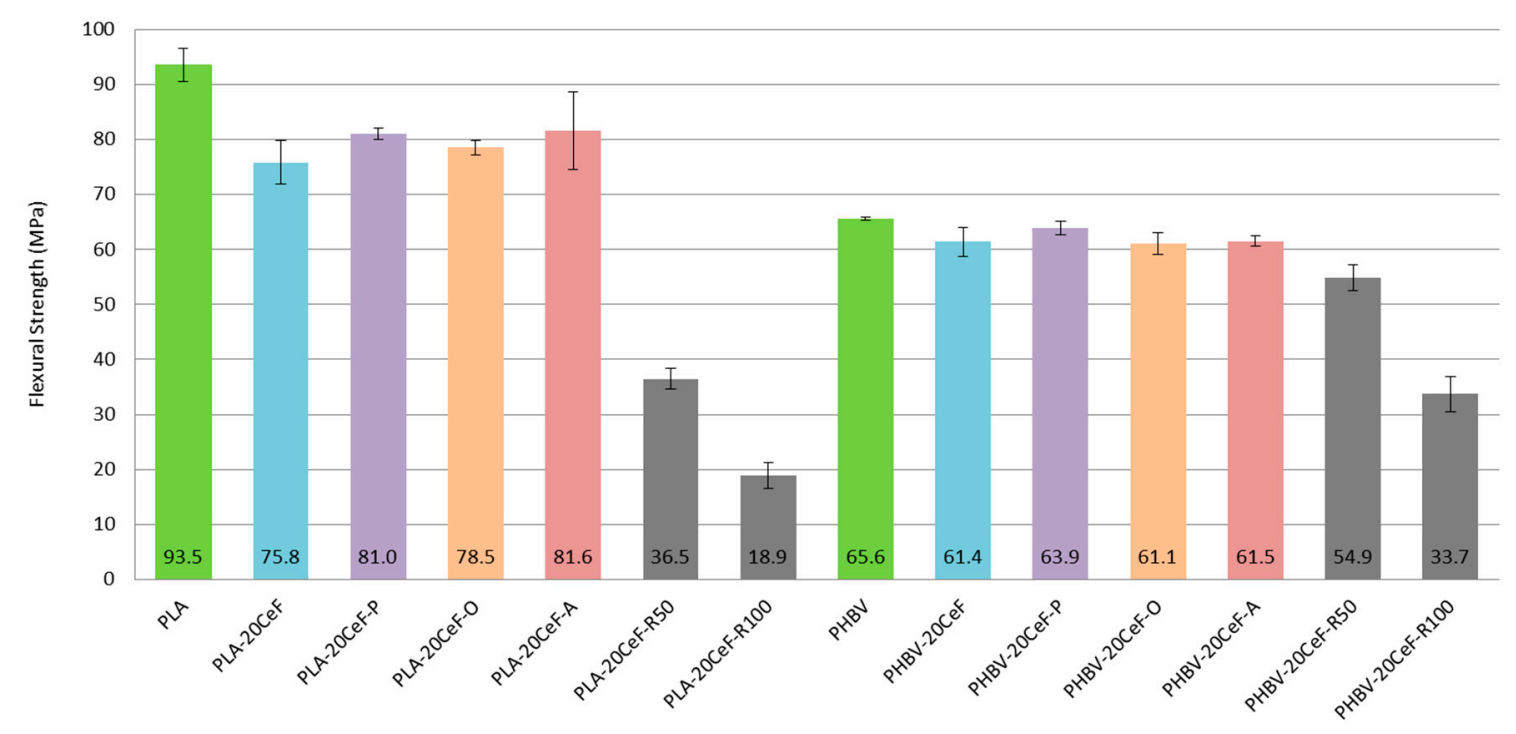

Figure 11. Flexural strength of PLA and PHBV biopolymer composites.

\subsection{Charpy Impact Properties}

The impact strength of both PLA and PHBV matrix was relatively low and the addition of natural cellulose fibers as a filler to the composite system further reduced this property. From the measured values (see Figure 12) it was evident that the addition of fibrous filler significantly reduced the impact strength from the point of view of the biocomposite structure as a whole. The results of impact measurements for the biocomposite structure with PLA matrix at a temperature of $+23^{\circ} \mathrm{C}$ show a significant loss of toughness by the addition of cellulose fibers, which was not affected by the method of surface modification of the natural filler. The decrease in impact strength was almost $50 \%$. In the case of a biocomposite with a PHBV matrix, the effect of the added cellulose fibers was also negative and the impact strength was reduced by an average of $20 \%$ compared to the unfilled PHBV matrix.

Due to the application of radiation crosslinking of the PLA composite, the impact toughness was further reduced: at a radiation value of $50 \mathrm{kGy}$ the impact toughness was only $40 \%$ and for a radiation value of $100 \mathrm{kGy}$ was only $10 \%$ of the impact toughness value relative to the unfilled PLA matrix. The decrease in impact strength when the radiation value was doubled, from 50 to $100 \mathrm{kGy}$, was then $65 \%$. The application of radiation crosslinking to a biocomposite with a PHBV matrix reduced the impact strength to $50 \%$ (at a radiation value of $50 \mathrm{kGy}$ ), respectively $40 \%$ (at a radiation value of 100 kGy) compared to an unfilled PHBV matrix. Thus, the application of radiation crosslinking in PLA and PHBV composites led to a further decrease in impact strength values, as the embrittlement of the matrix occurred. This conclusion corresponds with the published results [33,35], where an obvious decrease in impact strength was observed during the application of gamma radiation in PHBV biocomposites. 


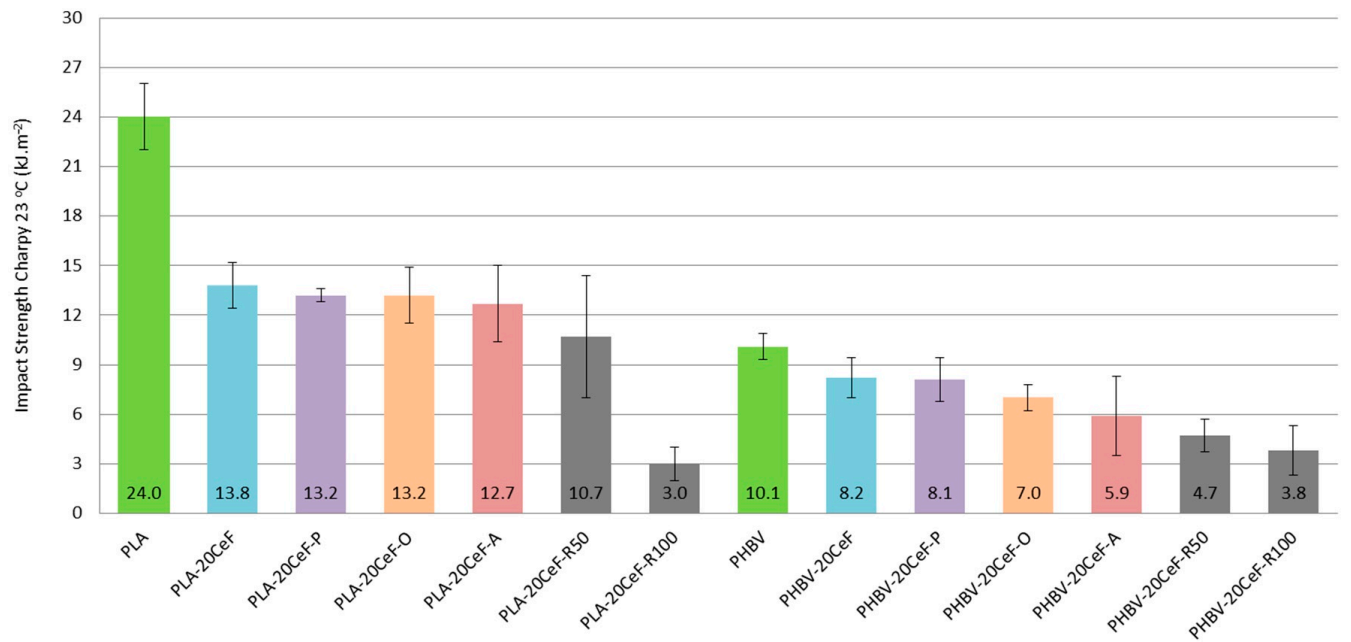

Figure 12. Impact strength Charpy of PLA and PHBV biopolymer composites.

\subsection{Characterization of Failure and Microscopy of Fracture Surfaces}

An important aspect of fibrous filler composites in terms of their application is not only the quality of interfacial adhesion between the fibers and the polymer matrix, which is a decisive factor in the use of fiber reinforcement potential (especially those strength-glass, carbon, etc., which find application in synthetic polymers), but also the evaluation of the fracture surface after modifications of the fiber surface and also after radiation crosslinking. Another important aspect of composite materials is the placement of the filler in the matrix, as the agglomeration of the filler causes inhomogeneity that degrade the reinforcing effect of the fibrous filler. SEM images of fracture surfaces of PLA and PHBV biopolymer composites with cellulose fibers without surface modification, with physical and chemical surface modification and also after radiation crosslinking were taken for evaluation of fracture surfaces and evaluation of interfacial adhesion at the interface of plant fibers and the biopolymer matrix. For the evaluation of fracture surfaces, Figure 13 shows images of fracture surfaces of PLA biocomposite structures without modification, Figures 14-16 show fracture surfaces of PLA biocomposites with cellulose fiber modification and Figure 17 images of fracture surfaces of PLA biopolymer composites after gamma radiation. Figure 18 shows images of fracture surfaces of biocomposite structures with the PHBV matrix without modification, Figures 19-21 show images of fracture surfaces of PHBV biocomposites with cellulose fiber modification and Figure 22 shows fracture surfaces of PHBV biopolymer composites after gamma radiation.

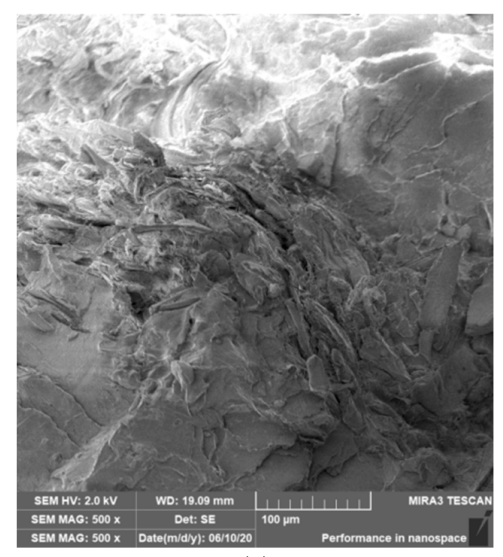

(a)

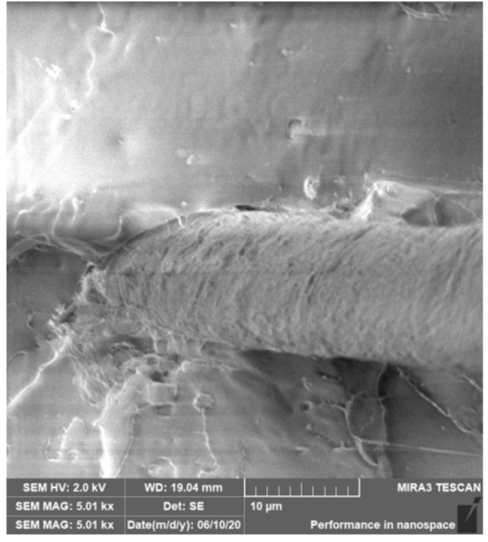

(b)

Figure 13. Microscopic image of fracture surfaces of biocomposite structure with the PLA matrix and cellulose fibers (CeFs) without modification of the fiber surface: fracture surface (a) and detail of the fiber-matrix interface (b), SEM. 


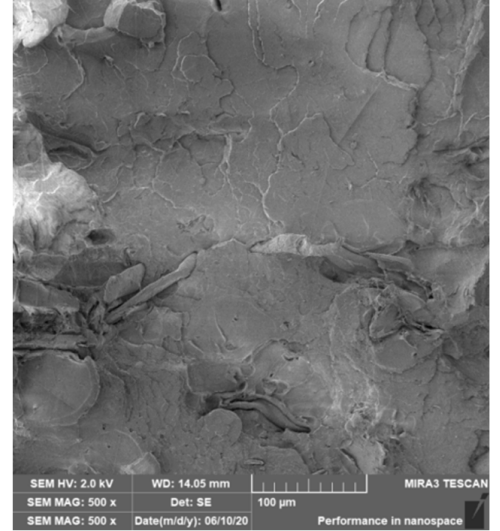

(a)

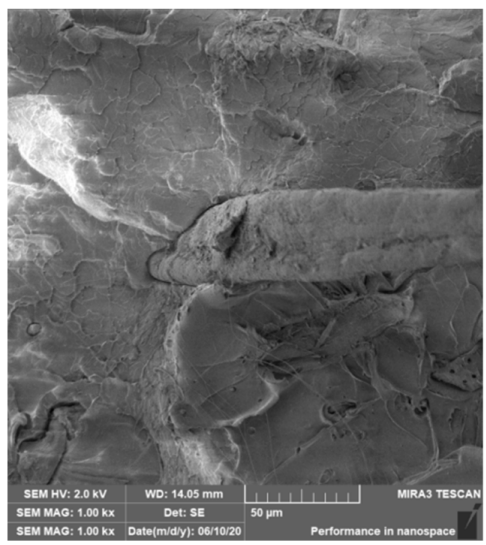

(b)

Figure 14. Microscopic image of fracture surfaces of the biocomposite structure with the PLA matrix and cellulose fibers $(\mathrm{CeFs})$ with plasma surface modification of fibers: fracture surface (a) and detail of the fiber-matrix interface $(\mathbf{b})$.

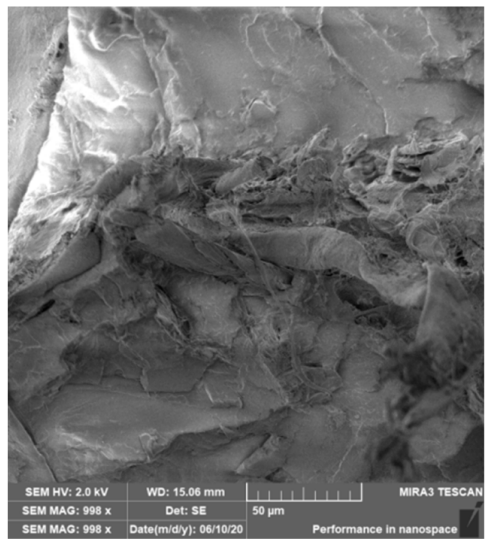

(a)

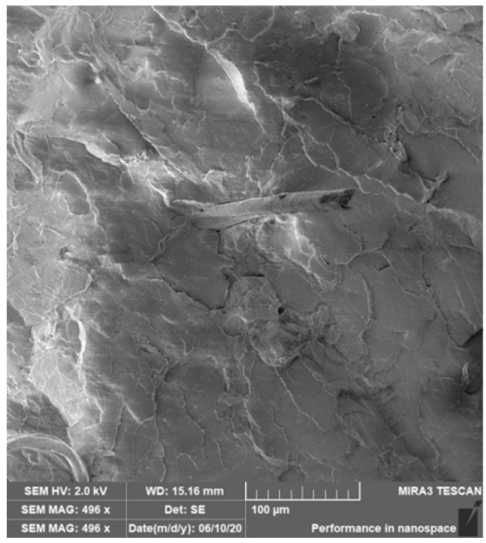

(b)

Figure 15. Microscopic image of fracture surfaces of a biocomposite structure with the PLA matrix and cellulose fibers (CeFs) with modification of the fiber surface by ozonation: fracture surface (a) and detail of the fiber-matrix interface (b).

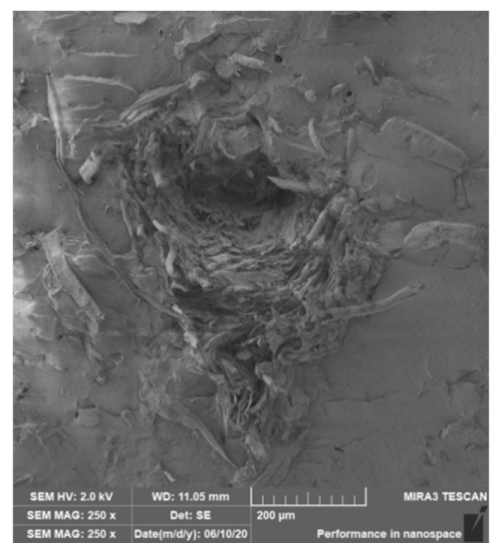

(a)

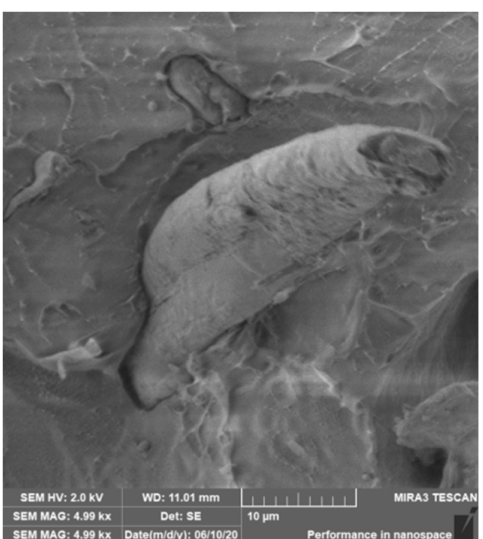

(b)

Figure 16. Microscopic image of fracture surfaces of the biocomposite structure with the PLA matrix and cellulose fibers with modification of the fiber surface by acetylation: fracture surface (a) and detail of the fiber-matrix interface (b). 


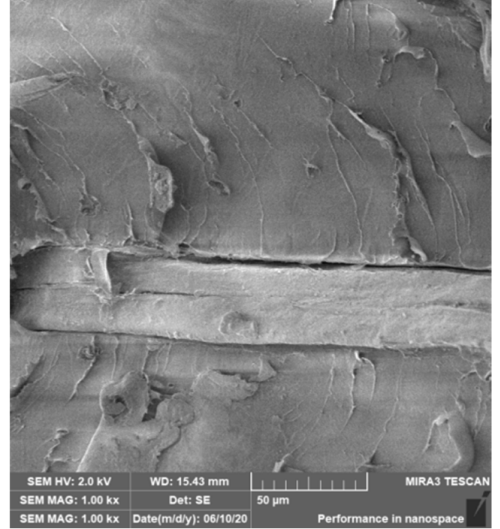

(a)

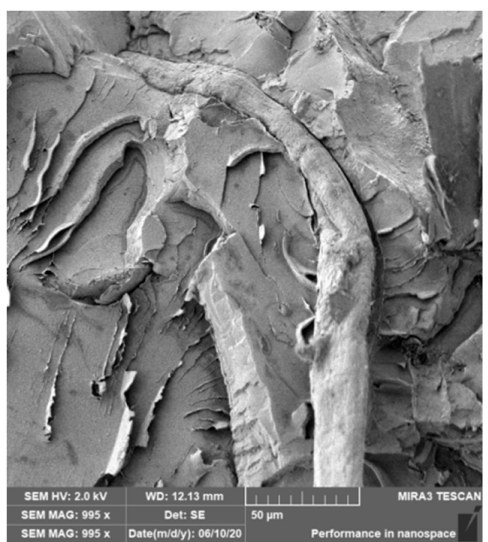

(b)

Figure 17. Microscopic image of fracture surfaces of the biocomposite structure with the PLA matrix and cellulose fibers (CeFs) after radiation crosslinking: $50 \mathrm{kGy}(\mathbf{a})$ and $100 \mathrm{kGy}(\mathbf{b})$, SEM.

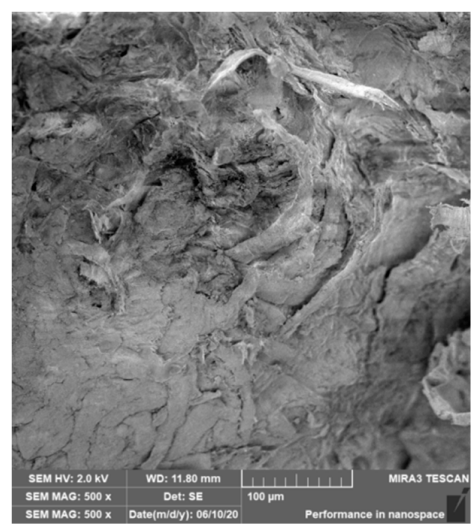

(a)

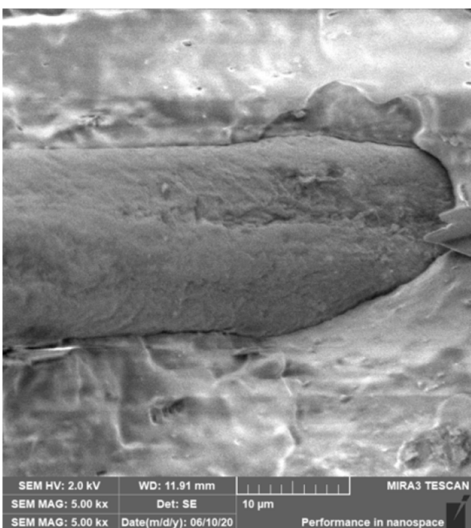

(b)

Figure 18. Microscopic image of fracture surfaces of the biocomposite structure with the PHBV matrix and cellulose fibers $(\mathrm{CeFs})$ without modification of the fiber surface: fracture surface (a) and detail of the fiber-matrix interface (b), SEM.

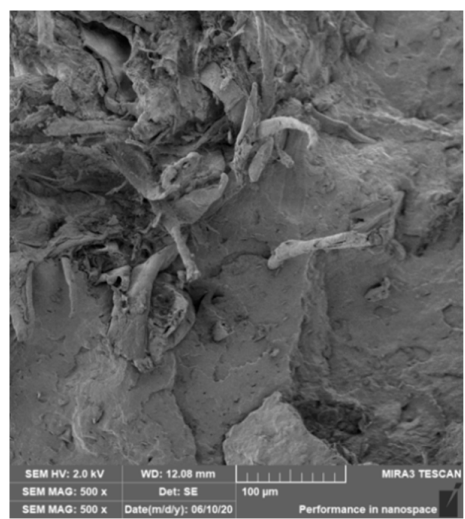

(a)

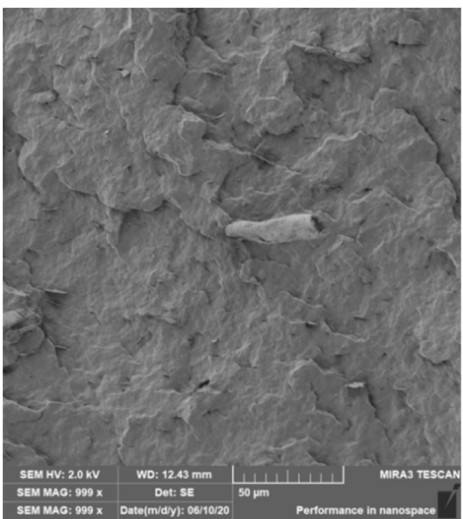

(b)

Figure 19. Microscopic image of fracture surfaces of biocomposite structure with the PHBV matrix and cellulose fibers (CeFs) with the plasma surface modification of fibers: fracture surface (a) and detail of the fiber-matrix interface $(\mathbf{b})$. 


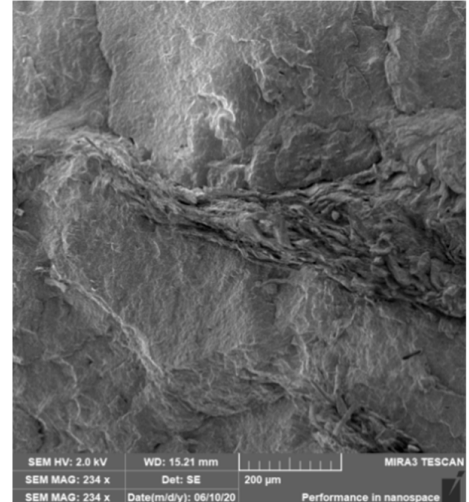

(a)

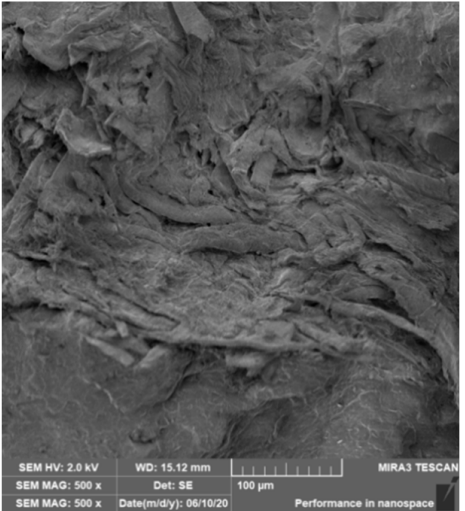

(b)

Figure 20. Microscopic image of fracture surfaces of the biocomposite structure with the PHBV matrix and cellulose fibers (CeFs) with modification of the fiber surface by ozonation: fracture surface (a) and detail of the fiber-matrix interface $(\mathbf{b})$.

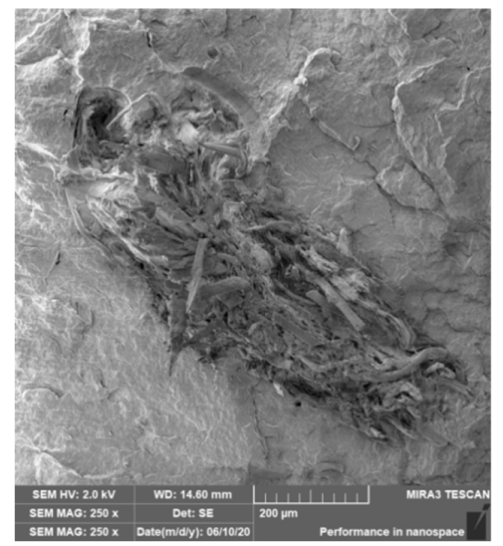

(a)

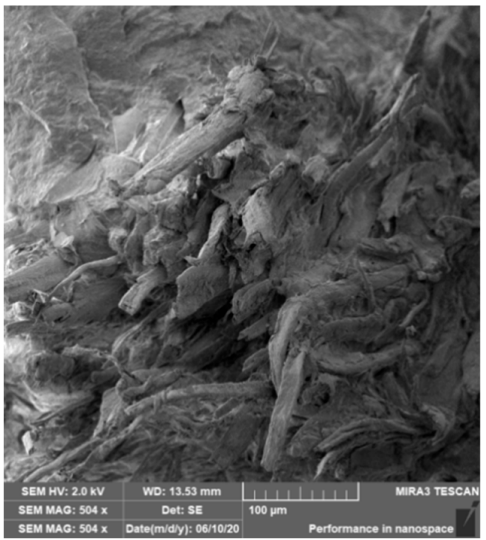

(b)

Figure 21. Microscopic image of fracture surfaces of the biocomposite structure with the PHBV matrix and cellulose fibers with modification of the fiber surface by acetylation: fracture surface (a) and detail of the fiber-matrix interface $(\mathbf{b})$.

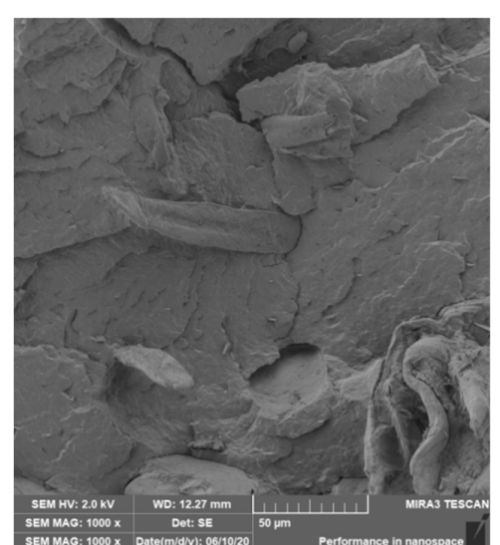

(a)

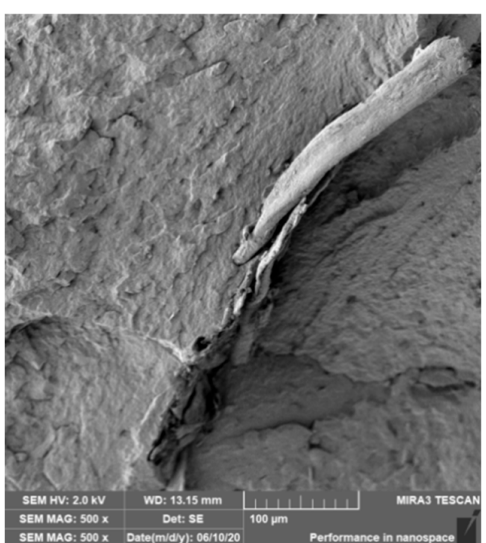

(b)

Figure 22. Microscopic image of fracture surfaces of the biocomposite structure with the PHBV matrix and cellulose fibers (CeFs) after radiation crosslinking: $50 \mathrm{kGy}(\mathbf{a})$ and $100 \mathrm{kGy}(\mathbf{b})$, SEM.

Microscopic images of the fracture surfaces of PLA biocomposites (see Figures 13-16) show that the fracture surface was not homogeneous and contained both clusters of fibers of hundreds of micrometers and individual fibers, both for cellulose fibers without surface modification, and surface-modified 
fibers. The fiber clusters were difficult to saturate and thus did not improve the mechanical properties that are standard in glass or carbon composites. The fiber clumps were then the weak points of the biocomposite where the failure occurred. After the application of surface modifications, the adhesion at the interfacial interface was improved, the matrix material partially enveloped the fiber reinforcement, but it was still not sufficient to increase the values of mechanical properties. The cellulose fibers themselves were torn, not drawn. The application of gamma radiation (see Figure 17) changed the character of the fracture, the character of the matrix changed. The brittle character of the fracture could be inferred from the fracture surface and it could also be seen that the adhesion to the fibers was very low.

Microscopic images of fracture surfaces of PHBV biocomposites (see Figures 18-21) show, similarly to PLA biocomposites, that the fracture surface was not homogeneous and contained both fiber clusters and individual fibers, both for cellulose fibers without surface modification and for surface-modified fibers. Clusters of fibers were critical places where fracture occurred. Additionally, as in the previous case, the fiber clusters were difficult to saturate. After the application of surface modifications, there was no significant improvement in adhesion at the interfacial interface. The application of gamma radiation (see Figure 22) to PHBV biocomposites changed the nature of the refraction (especially with a high value of gamma radiation of $100 \mathrm{kGy}$ ), the fracture surface shows a brittle nature of the refraction. When applying gamma radiation of $50 \mathrm{kGy}$, it is a tough refraction, but the nature of the refraction was different compared to the matrix without irradiation.

\section{Conclusions}

In recent years, biopolymer composites have become the focus of a wide range of research activities, material manufacturers, processors and end users. Biocomposite materials based on PLA and PHB matrices and plant fibers have great potential for wide application use and are beginning to gain in importance. In the case of biocomposites, two important sectors can be distinguished, in which products are used in technical applications and in medical applications. The use of biocomposites and natural fibers in technical applications offers wide possibilities for technical innovation and sustainable development. Today, they are no longer just biodegradable packaging, foils and disposable products, but recently, there have been a significant demand for these composites for various technical products, such as automotive parts, furniture components, design products and electrical engineering, but also in the aerospace industry. Polymer composites with the biopolymer matrix and natural fibers have increasingly been used mainly in interior applications in terms of environmental requirements and environmental sustainability.

Experimental results obtained from the evaluation of mechanical parameters concerning prepared biocomposite systems were related to the chemical composition of used matrices, type and shape of filler-cellulose fibers, percentage of fibers, fiber surface treatments, fiber adhesion to polymer matrices, homogeneity of fiber distribution in polymer matrix, fracture character and also radiation that was used to crosslink selected samples.

The application of surface modifications to cellulose fibers did not achieve the expected effects known from other commercially available fibers. There were no major morphological changes at the fiber surface level that would have a determining effect on the adhesion of the fibers to the polymers. There appeared to have been chemical changes (opening of surface bonds leading to a change in hydrophilicity/hydrophobicity), which, however, were insufficient to significantly affect and improve adhesion at the fiber-polymer interface, especially in the PLA matrix. Based on the achieved results, with some exceptions, there were no positive changes in terms of increasing mechanical parameters. At the same time, conclusions from other publications and studies were confirmed.

The chemical composition of the used PLA and PHBV matrices, which was different, had a significant effect not only on the adhesion at the interfacial interface, but also on the final properties after radiation crosslinking. In terms of mechanical properties, better values of mechanical properties 
were achieved for the PHBV matrix both in adhesion and the effects of gamma radiation. The results were confirmed and at the same time, expanded knowledge in this area.

The addition of $20 \%$ cellulose fibers did not significantly improve the evaluated mechanical parameters. This fact can be explained by a number of factors and their combination. Cellulose fibers of the above dimensions were not straight, so they were easily intertwined, which was initiated by a change in surface tension for the modifications made and, last but not least, by the method of preparation (temperature-pressure processes) of test specimens. As a result of the formation of cellulose agglomerates, there was no uniform dispersion, the cellulose agglomerates could then function as weak points, especially if they were not coated with a polymer matrix where the breakdown occurred. These effects were also observed in other experimental work.

During the process of radiation crosslinking, bonds were broken down and free radicals were formed. Following the formation of free radicals, other processes might occur, such as cleavage of macromolecular chains or interconnection of macromolecular chains, or both. Which process will predominate will be related to the chemical composition of the polymer, the ratio of amorphous and semicrystalline regions, or the presence of the filler and its chemical composition, the dose of radiation used and the process conditions. Polymers that contain an oxygen atom in the backbone are more sensitive to radiation in the negative sense of the word. Cellulose is also sensitive to the effects of radiation. Based on the chemical composition, it can therefore be assumed that the polymer crosslinks will degrade or shorten during radiation crosslinking. These theoretical assumptions, which were also found in the above studies, were confirmed by measurement in the PLA matrix. On the contrary, in the case of the PHBV matrix, radiation crosslinking had a rather positive impact and negative effects occurred only due to high radiation values.

The acquired knowledge about biopolymer composites, their structures, constructions and modifications, including knowledge about the characterization of mechanical properties, behavior under load and fracture behavior is important both in terms of advanced application possibilities but also in terms of biopolymer composites as progressive materials with a wide range of environmental benefits.

Author Contributions: Conceptualization, P.L., P.B., M.B., L.B. and J.H.; methodology, P.L., M.B., L.B. and J.H.; software, L.B.; validation, P.L., P.B. and M.B.; formal analysis, P.L., P.B., M.B., and L.B.; investigation, P.L., P.B., M.B., L.B. and J.H.; resources, P.L., P.B. and M.B.; data curation, P.L. and L.B.; writing-original draft preparation, P.L., P.B. and M.B.; writing-review and editing, P.L., P.B., M.B. and L.B.; supervision, P.L., P.B., and M.B.; project administration, P.L., P.B., M.B. and L.B.; funding acquisition, P.L., P.B., M.B. and L.B. All authors have read and agreed to the published version of the manuscript.

Funding: This research was funded by the [Ministry of Education, Youth and Sports of the Czech Republic and the European Union-European Structural and Investment Funds in the frames of Operational Program Research, Development and Education]— project Hybrid Materials for Hierarchical Structures [HyHi, Reg. No. CZ.02.1.01/0.0/0.0/16_019/0000843].

Conflicts of Interest: The authors declare no conflict of interest.

\section{References}

1. Kalia, S.; Dufresne, A.; Cherian, B.M.; Kaith, B.S.; Avérous, L.; Njuguna, J.; Nassiopoulos, E.; Leiza, J.R. Cellulose-Based Bio- and Nanocomposites. Int. J. Polym. Sci. 2011, 2011, 1-35. [CrossRef]

2. Ganapini, W. Bioplastics: A Case Study of Bioeconomy in Italy; Edizioni Ambiente: Milano, Italy, 2014.

3. Watkins, E.; Schweitzer, J.-P. Moving Towards a Circular Economy for Plastics in the EU by 2030. Think 2030; Institute for European Environmental Policy (IEEP): Brussels, Belgium, 2018.

4. La Mantia, F.P.; Morreale, M. Green composites: A brief review. Compos. Part A Appl. Sci. Manuf. 2011, 42, 579-588. [CrossRef]

5. Marsh, G. Next step for automotive materials. Mater. Today 2003, 4, 36-43. [CrossRef]

6. Oliveux, G.; Dandy, L.O.; Leeke, G.A. Current status of recycling of fibre reinforced polymers: Review of technologies, reuse and resulting properties. Prog. Mater. Sci. 2015, 72, 61-99. [CrossRef]

7. Rybicka, J.; Tiwari, A.; Leeke, G.A. Technology readiness level assessment of composites recycling technologies. J. Clean. Prod. 2016, 112, 1001-1012. [CrossRef] 
8. Mohanty, A.K.; Misra, M.; Hinrichsen, G.I. Biofibres, biodegradable polymers and biocomposites: An overview. Macromol. Mater. Eng. 2000, 276, 1-24. [CrossRef]

9. Netravali, A.N.; Chabba, S. Composites get greener. Mater. Today 2003, 4, 22-29. [CrossRef]

10. Jimenez, A.; Peltzer, M.; Ruseckaite, R. Poly (Lactic Acid) Science and Technology: Processing, Properties, Additives and Applications; Royal Society of Chemistry: London, UK, 2014.

11. Pei, A.; Zhou, Q.; Berglund, L.A. Functionalized cellulose nanocrystals as biobased nucleation agents in poly(l-lactide) (PLLA)—Crystallization and mechanical property effects. Compos. Sci. Technol. 2010, 70, 815-821. [CrossRef]

12. Nanda, M.R.; Manjusri, M.; Mohanty, A.K. The effects of process engineering on the performance of PLA and PHBV blends. Macromol. Mater. Eng. 2011, 296, 719-728. [CrossRef]

13. Boufarguine, M.; Guinault, A.; Miquelard-Garnier, G.; Sollogoub, C. PLA/PHBV films with improved mechanical and gas barrier properties. Macromol. Mater. Eng. 2013, 298, 1065-1073. [CrossRef]

14. Khanna, S.; Srivastava, A.K. Recent advances in microbial polyhydroxyalkanoates. Process Biochem. 2005, 40, 607-619. [CrossRef]

15. Mwaikambo, L.Y. Review of the history and application of plant fibre. Afr. J. Sci. Technol. 2006, 7, 120-133.

16. Mochane, M.J.; Mokhena, T.C.; Sadiku, E.R.; Ray, S.S.; Mofokeng, T.G. Green Polymer Composites Based on Polylactic Acid (PLA) and Fibers. Green Biopolymers and their Nanocomposites; Springer: Singapore, 2019; pp. 29-54.

17. Mwaikambo, L.Y.; Ansell, M.P. Chemical modification of hemp, sisal, jute, and kapok fibers by alkalization. J. Appl. Polym. Sci. 2002, 84, 2222-2234. [CrossRef]

18. Kalia, S.; Kaith, B.S.; Kaur, I. Cellulose Fibers: Bio-and Nano-Polymer Composites: Green Chemistry and Technology; Springer Science \& Business Media: Berlin/Heidelberg, Germany, 2011. [CrossRef]

19. Mehta, G.; Drzal, L.T.; Mohanty, A.K.; Misra, M. Effect of fiber surface treatment on the properties of biocomposites from nonwoven industrial hemp fiber mats and unsaturated polyester resin. J. Appl. Polym. Sci. 2006, 99, 1055-1068. [CrossRef]

20. Tserki, V.; Panayiotou, C.; Zafeiropoulos, N.E. A study of the effect of acetylation and propionylation surface treatments on natural fibres. Compos. Part A Appl. Sci. Manuf. 2005, 36, 1110-1118. [CrossRef]

21. Mishra, S.; Naik, J.B.; Patil, Y.P. The compatibilising effect of maleic anhydride on swelling and mechanical properties of plant-fiber-reinforced novolac composites. Compos. Sci. Technol. 2000, 60, 1729-1735. [CrossRef]

22. Ferreira, D.P.; Cruz, J.; Fangueiro, R. Surface modification of natural fibers in polymer composites. In Green Composites for Automotive Applications; Woodhead Publishing: Cambridge, UK, 2019; pp. 3-41.

23. Kalia, S.; Thakur, K.; Celli, A.; Kiechel, M.A.; Schauer, C.L. Surface modification of plant fibers using environment friendly methods for their application in polymer composites, textile industry and antimicrobial activities: A review. J. Environ. Chem. Eng. 2013, 1, 97-112. [CrossRef]

24. Sun, D. Surface modification of natural fibers using plasma treatment. In Biodegradable Green Composites; Kalia, S., Ed.; Wiley: Hoboken, NJ, USA, 2016; pp. 18-39. [CrossRef]

25. Thakur, V.K.; Singha, A.S. Surface Modification of Biopolymers; Wiley: Hoboken, NJ, USA, 2015. [CrossRef]

26. Oliveira, D.M.; Benini, K.C.C.C.; Monticeli, F.M.; Schukraft, J.P.; Bomfim, A.S.C.; Cioffi, M.O.H.; Voorwald, H.J.C. Permeability of untreated and atmospheric plasma treated coconut fiber mats. Mater. Res. Express 2019, 6, 095323. [CrossRef]

27. Borůvka, M.; Ngaowthong, C.; Bĕhálek, L.; Habr, J.; Lenfeld, P. Effect of dielectric barrier discharge plasma surface treatment on the properties of pineapple leaf fiber reinforced poly (lactic acid) biocomposites. Mater. Sci. Forum 2016, 862, 156-165. [CrossRef]

28. Běhálek, L.; Borůvka, M.; Brdlík, P.; Habr, J.; Lenfeld, P.; Kroisová, D.; Veselka, F.; Novák, J. Thermal properties and non-isothermal crystallization kinetics of biocomposites based on poly (lactic acid), rice husks and cellulose fibres. J. Therm. Anal. Calorim. 2020, 142, 629-649. [CrossRef]

29. Maqsood, H.S.; Bashir, U.; Wiener, J.; Puchalski, M.; Sztajnowski, S.; Militky, J. Ozone treatment of jute fibers. Cellulose 2017, 24, 1543-1553. [CrossRef]

30. Reig, F.B.; Gimeno-Adelantado, J.V.; Moreno Moya, M.C.M. FTIR quantitative analysis of calcium carbonate (calcite) and silica (quartz) mixtures using the constant ratio method. Application to geological samples. Talanta 2002, 58, 811-821. [CrossRef] 
31. Zembouai, I.; Kaci, M.; Bruzaud, S.; Pillin, I. Electron beam radiation effects on properties and ecotoxicity of PHBV/PLA blends in presence of organo-modified montmorillonite. Polym. Degrad. Stab. 2016, 132, 117-126. [CrossRef]

32. Tiptipakorn, S.; Hemvichain, K.; Pirombua, A. Study of the effect of electron beam on thermal and mechanical properties of poly (lactic acid)/poly (butylene succinate) blends. IOP Conf. Ser. Mater. Sci. Eng. 2019, 526, 012012. [CrossRef]

33. Luo, S.; Netravali, A.N. Effect of ${ }^{60} \mathrm{Co} \gamma$-radiation on the properties of poly (hydroxybutyrate-cohydroxyvalerate). J. Appl. Polym. Sci. 1999, 73, 1059-1067. [CrossRef]

34. Oliveira, L.M.; Araujo, E.S.; Guedes, S.M. Gamma irradiation effects on poly (hydroxybutyrate). Polym. Degrad. Stab. 2006, 91, 2157-2162. [CrossRef]

35. Oliveira, L.M.; Araujo, P.L.B.; Araujo, E.S. The effect of gamma radiation on mechanical properties of biodegradable polymers poly (3-hydroxybutyrate) and poly (3-hydroxybutyrate-co-3-hydroxyvalerate). Mater. Res. 2013, 16, 195-203. [CrossRef]

36. Malinowski, R.; Rytlewski, P.; Żenkiewicz, M. Effects of electron radiation on properties of PLA. Arch. Mater. Sci. 2011, 49, 25-32.

37. Meihua, L.; Wanxi, Z.; Yuan, Y.; Wei, W.; Chunbai, Z.; Pengyang, D.; Shirley, S. Effects of radiation-induced crosslinking on thermal and mechanical properties of poly (lactic acid) composites reinforced by basalt fiber. Asia-Pac. Symp. Radiat. Chem. 2013, 24 (Suppl. 1), 6.

38. Dadbin, S.; Naimian, F.; Akhavan, A. Poly (lactic acid)/layered silicate nanocomposite films: Morphology, mechanical properties, and effects of $\gamma$-radiation. J. Appl. Polym. Sci. 2011, 122, 142-149. [CrossRef]

39. Dadbin, S.; Naimian, F.; Akhavan, A.; Hasanpoor, S. Poly(Lactic Acid)/Layered Silicate Nanocomposite Films: Effect of Irradiation; Report of the 2nd RCM on Nanoscale radiation engineering of advanced materials for potential biomedical applications; International Atomic Energy Agency (IAEA): Vienna, Austria, 2010.

40. Iggui, K.; Kaci, M.; Mahlous, M.; Moigne, N.L.; Bergeret, A. The Effects of Gamma Irradiation on Molecular Weight, Morphology and Physical Properties of PHBV/Cloisite 30B Bionanocomposites. J. Renew. Mater. 2019, 7, 807-820. [CrossRef]

Publisher's Note: MDPI stays neutral with regard to jurisdictional claims in published maps and institutional affiliations.

(C) 2020 by the authors. Licensee MDPI, Basel, Switzerland. This article is an open access article distributed under the terms and conditions of the Creative Commons Attribution (CC BY) license (http://creativecommons.org/licenses/by/4.0/). 